\title{
Trypanosoma brucei ATPase subunit 6 mRNA bound to gA6-14 forms a conserved three-helical structure
}

\author{
LARISSA REIFUR ${ }^{1}$ and DONNA J. KOSLOWSKY ${ }^{1,2}$ \\ ${ }^{1}$ Comparative Medicine and Integrative Biology, College of Veterinary Medicine, Michigan State University, East Lansing, Michigan 48824, USA \\ ${ }^{2}$ Microbiology and Molecular Genetics, Michigan State University, East Lansing, Michigan 48824, USA
}

\begin{abstract}
T. brucei survival relies on the expression of mitochondrial genes, most of which require RNA editing to become translatable. In trypanosomes, RNA editing involves the insertion and deletion of uridylates, a developmentally regulated process directed by guide RNAs (gRNAs) and catalyzed by the editosome, a complex of proteins. The pathway for mRNA/gRNA complex formation and assembly with the editosome is still unknown. Work from our laboratory has suggested that distinct mRNA/gRNA complexes anneal to form a conserved core structure that may be important for editosome assembly. The secondary structure for the apocytochrome $b(\mathrm{CYb})$ pair has been previously determined and is consistant with our model of a three-helical structure. Here, we used cross-linking and solution structure probing experiments to determine the structure of the ATPase subunit 6 (A6) mRNA hybridized to its cognate gA6-14 gRNA in different stages of editing. Our results indicate that both unedited and partially edited A6/gA6-14 pairs fold into a three-helical structure similar to the previously characterized $\mathrm{CYb} /$ gCYb-558 pair. These results lead us to conclude that at least two mRNA/gRNA pairs with distinct editing sites and distinct primary sequences fold to a three-helical secondary configuration that persists through the first few editing events.
\end{abstract}

Keywords: Trypanosoma brucei; ATPase 6; RNA-RNA interaction; RNA structure; RNA editing

\section{INTRODUCTION}

Trypanosoma brucei is a protozoan parasite that undergoes mitochondrial RNA editing to survive. This posttranscriptional modification is unique to kinetoplastids and involves site-specific uridylate (U) insertions and deletions to correct encoded frameshifts, create translation start and stop codons, and extend open reading frames (for reviews, see Simpson et al. 2003; Stuart et al. 2005). In T. brucei, 12 of the 18 mRNAs require editing, but the extent and control of the modification vary according to the message and life cycle of the parasite. Short (50-70 nucleotides [nt]) guide RNAs (gRNA) with complementarity to segments of pre-edited or partially edited mRNAs provide the sequence information necessary for the precise modifications (Blum et al. 1990). Each gRNA has three functionally distinct domains that seem to fold onto a similar structure containing one to two stem-loops (Schmid et al. 1995;

Reprint requests to: Donna J. Koslowsky, Comparative Medicine and Integrative Biology, College of Veterinary Medicine, Michigan State University, 2209 Biomedical and Physical Sciences, East Lansing, MI 48824, USA; e-mail: koslowsk@msu.edu; fax: (517) 353-8957.

Article published online ahead of print. Article and publication date are at http://www.rnajournal.org/cgi/doi/10.1261/rna.1144508.
Yu and Koslowsky 2006). The gRNA anchor domain at the $5^{\prime}$-end (4-16 nt) is complementary to the anchor-binding site (ABS) within the mRNA. Hybridization of gRNA anchor and ABS forms the anchor helix, which is fundamental for editing initiation. The first mismatch $5^{\prime}$ of the anchor helix (mRNA orientation) is the presumed first editing site (ES). At the opposing gRNA end, there is the 3 '-oligo (U) tail (U-tail) domain (5-24 nt) that is added post-transcriptionally and thought to tether the purine-rich region of the mRNA and form the U-tail helix (Blum and Simpson 1990; Seiwert et al. 1996; Leung and Koslowsky 1999; 2001b). Joining the anchor helix and the U-tail helix is the central portion of the gRNA, or guiding domain, which dictates the type of editing (insertion or deletion) and the number of U's involved in the process. Annealing of the gRNA to the mRNA is proposed to form a threehelical structure that defines the editing site (Leung and Koslowsky 2001a,b; Yu and Koslowsky 2006) and allows editing to proceed mostly from $3^{\prime}$ to $5^{\prime}$ within the mRNA (Abraham et al. 1988; Sturm and Simpson 1990; Koslowsky et al. 1991; Maslov and Simpson 1992).

The three-helical structure was not initially predicted to exist in distinct mRNA/gRNA pairs. Studies using computer programs to obtain secondary structures for different 
mRNA/gRNA hybrids found no consensus secondary structure among the complexes (Blum and Simpson 1990; Leung and Koslowsky 1999). Only after cross-linking three gRNAs to their respective cognate mRNAs and incorporating the constraints into a computer modeling program were all three pairs shown to fold into a three-helical structure (Leung and Koslowsky 1999) similar to the structure of a fourth mRNA/gRNA pair confirmed previously by S1 protection assay (Blum and Simpson 1990). Through cross-linking and structure probing studies, a secondary structure model has been proposed for a $\mathrm{CYb}$ mRNA/gRNA pair (Leung and Koslowsky 2001a,b; Yu and Koslowsky 2006), and it shows the persistence of three helices even after editing of the first sites, raising the importance of this organization.

Editing involves a cascade of coordinated steps catalyzed by the editosome, a multiprotein complex that can be isolated and enriched from kinetoplastid mitochondria (Pollard et al. 1992; Corell et al. 1996; Rusche et al. 1997; Simpson et al. 2004). Editosomes can be divided into insertion and deletion subcomplexes (Schnaufer et al. 2003; Panigrahi et al. 2006), which optimally work under distinct conditions (Cruz-Reyes et al. 1998). A third editosome has been found to specifically cleave insertion sites when the gRNA appears in cis (Panigrahi et al. 2007; Carnes et al. 2008). Each editosome has unique proteins such as a specific endonuclease and a structural protein. Nonetheless, all subcomplexes share numerous structural and catalytic proteins and have the three enzymatic activities required for editing: endonuclease, terminal uridylyl transferase or 3' exonuclease, and ligase. In addition, accessory factors, such as RBP16 and the MRP complex, have been shown to transiently interact with the editosome and indirectly affect editing (Koller et al. 1997; Blom et al. 2001; Aphasizhev et al. 2003; Panigrahi et al. 2003; Vondruskova et al. 2005; Miller et al. 2006; Ammerman et al. 2008; Zikova et al. 2008). Although RBP16 and the MRP complex have been shown to facilitate the annealing of a few mRNA/gRNAs, in vitro full-round and precleaved editing assays are conducted with purified editosomes in the absence of these or other proteins (Seiwert and Stuart 1994; Cruz-Reyes and Sollner-Webb 1996; Igo et al. 2000; Kang et al. 2005).

Despite all the progress, there are unanswered questions concerning the temporal association of gRNAs and mRNAs with the editosome and what triggers the editing cascade. It has been suggested that gRNAs and mRNAs are initially bound to protein complexes and then brought together to assemble into a binary complex away from the editosome (Zikova et al. 2008) or within the editosome (MadisonAntenucci et al. 2002). Alternatively, the mRNA/gRNA complexes could form in the absence of proteins and be the signal for editosome recognition and editing (Blum and Simpson 1990; Rusche et al. 1997; Leung and Koslowsky 1999; Yu and Koslowsky 2006).
The three-helical model proposed by our laboratory is believed to fit several mRNA/gRNA pairs. Here we determined the secondary structure of the A6/gA6-14 pair during different stages of editing using both cross-linking and solution structure probing methods. Like the previously described $\mathrm{CYb}$ pair, the A6 pair folds into a threehelical structure that is maintained during the initial stages of editing. However, in contrast to the CYb pair that only undergoes insertional editing, the A6 pairs studied had the editing sites of the deletion type. The highly organized structure observed within the editing sites in A6 and CYb binary complexes may provide new insights into a mechanism for editing site specificity.

\section{RESULTS}

\section{Description of RNAs}

The ATPase subunit 6 (A6) transcript is extensively and constitutively edited throughout the parasite's life cycle (Bhat et al. 1990). The mRNA used in this study contains the natural sequence from the $3^{\prime}$-end of T. brucei A6. We used both the unedited A6ㅁ and the partially edited through $\underline{3}$ sites $\mathrm{A} 6 \underline{\mathrm{P} 3}$ substrates (Fig. 1). Editing of this domain is initiated by gA6-14, and both the mRNA and gRNA have been previously described (Leung and Koslowsky 1999) and extensively used in editing assays in vitro (Seiwert and Stuart 1994; Cruz-Reyes and Sollner-Webb 1996; Kable et al. 1996; Seiwert et al. 1996). While the

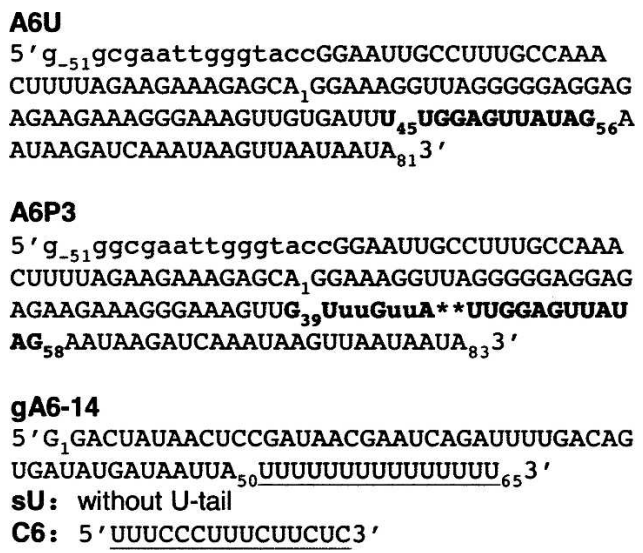

FIGURE 1. A6 mRNAs and gRNAs. Both unedited (A6U) and partially edited through $\underline{3}$ sites (A6 $\underline{\mathrm{P}} 3$ ) mRNAs are highlighted at the anchor binding site (ABS), which is complementary to the $5^{\prime}$-end (anchor) of gA6-14. A6P3 differs from A6U in the deletion of two uridylates at ES1 (asterisks) and four inserted uridylates at ES2 and ES3 (highlighted lowercase). In order to coordinate the numbering of the different substrates used, the shorter mRNA sequences were numbered starting with the $5^{\prime}$-most nucleotide as number 1 or $A_{1}$. Nucleotides found upstream of $A_{1}$ in the longer substrates were negative numbers (up to $\mathrm{G}_{-51}$ ). The underlined sequence within gA614 indicates the U-tail. The suffix sU for gA6-14 indicates absence of U-tail and C6 corresponds to modified U-tail. The mRNA nucleotides in lowercase at the $5^{\prime}$-end are vector sequence. 
$5^{\prime}$-end of the gRNA specifically binds the mRNA ABS, and its middle portion directs editing, the role of the gRNAs $3^{\prime}$-end, or U-tail is less clear. It is hypothesized to tether the purine-rich region upstream of the mRNA editing site (Blum and Simpson 1990; Leung and Koslowsky 1999), facilitating ligation of the mRNA pieces after editing (Seiwert et al. 1996). Mutations strengthening the U-tail binding improved $U$ insertion (Burgess et al. 1999; Kapushoc and Simpson 1999; Igo et al. 2000) while U deletions were inhibited in some experiments (Seiwert et al. 1996) but increased in others (Cruz-Reyes et al. 2001). This can be explained by the fact that the U-tail differentially contributes to the binding affinity of distinct mRNA/gRNA pairs (Koslowsky et al. 2004). Because of the curious influence of the U-tail on editing, we included in our experiments two variations of gA6-14, one with deleted $\mathrm{U}$-tail (gA6-14sU) and another with $6 \mathrm{U}$-to-C mutations (gA6-14-C6) that strengthens U-tail binding. gA6-14-C6 has been previously published as $\mathrm{g}[2,1]+6 \mathrm{C}$, and it was shown to increase deletion editing efficiency fourfold when compared to gA6-14 (Cruz-Reyes et al. 2001).

\section{gRNA U-tail interactions with mRNA}

\section{Cross-linking of $m R N A / g R N A$}

In vivo, gRNA U-tails are heterogeneous in size, averaging 15 U's (Blum and Simpson 1990). In vitro synthesized gRNA containing a U-tail with $10 \mathrm{U}$ 's $\left(\mathrm{U}_{10}\right.$-tail $)$ had previously been used in cross-link studies to map the Utail binding site within different mRNAs. Leung and Koslowsky $(1999,2001 \mathrm{a})$ attached the APA cross-linking agent to the $3^{\prime}$-end of the gRNA containing a $\mathrm{U}_{10}$-tail and cross-linked the gRNA to the mRNA with UV irradiation. They observed that the U-tail interacted with the purinerich region (4-15 nt) upstream of the editing site using three distinct mRNA/gRNA pairs. With the purpose of having an mRNA/gRNA interaction closer to what is seen in vivo, in this study we used an $\mathrm{U}_{15}$-tail and the mRNA with native sequence. The U-tail was chemically synthesized (Dharmacon Research) containing the cross-linking agent 4-thio-U group $\left(S^{4} \mathrm{U}\right)$ at the 5 th or 10th $\mathrm{U}$, counting from the $5^{\prime}$-end. These U5 and U10 modified tails were $5^{\prime}$-end radioactively labeled with $\left[\gamma^{-}{ }^{32} \mathrm{P}\right] \mathrm{ATP}$, ligated to gA6-14sU (hence called gA6-14-U5 and gA6-14-U10), and gel purified. Half of the recovered samples received further treatment with azidophenacyl bromide (APA). APA is coupled to the thio group to increase the range of cross-links from $0 \AA$ to $9 \AA$ (Thomas et al. 2000). The gRNAs, gA6-14-U5 and gA6-14-U10, with $S^{4} U$ or APA, were then hybridized to A6U and A6P3 under editing conditions, followed by UV irradiation for $20 \mathrm{~min}$ on ice as previously described (Burgin and Pace 1990; Leung and Koslowsky 1999). Through denaturing gel purification, we observed that the cross-linked $(\mathrm{x})$ molecules for both mRNAs divided into two populations (B1 and B2) with distinct mobilities (Fig. 2). B1 cross-links were more efficient than B2, except for A6U x gA6-14-U10 (see explanation under Primer extension of cross-linked mRNA/gRNA, below). Regarding the abundance of cross-linked molecules, addition of the APA group increased the cross-linking efficiency in comparison to $S^{4} U$, as expected. $S^{4} U$ is a zero length agent that only efficiently cross-links to single-stranded regions, a characteristic that decreases the cross-linking efficiency but generates precise results (Dubreuil et al. 1991; Favre et al. 1998). While the addition of APA increased the amount of B1 over fivefold, only a modest increase was observed in the B2 population.

\section{Primer extension of cross-linked mRNA/gRNA}

The cross-linked molecules were gel purified and analyzed by primer extension as previously described (Leung and Koslowsky 1999). The reverse transcriptase (RT) is halted one base prior to the cross-link, aborting a product that can be mapped on a denaturing polyacrylamide gel. This procedure allows identification of the cross-link site with single nucleotide definition (Sontheimer 1994). As previously reported, we observed bands in the controls not exposed to UV irradiation (data not shown), but they were artifacts due to premature stoppage of the RT at structural elements in the mRNA sequence (Sontheimer 1994). Thus, a true cross-linked site was considered only when the band was stronger than the corresponding band on the control in multiple experiments. In addition to primer extension, we conducted ribonuclease (RNase) $\mathrm{H}$ assays to confirm

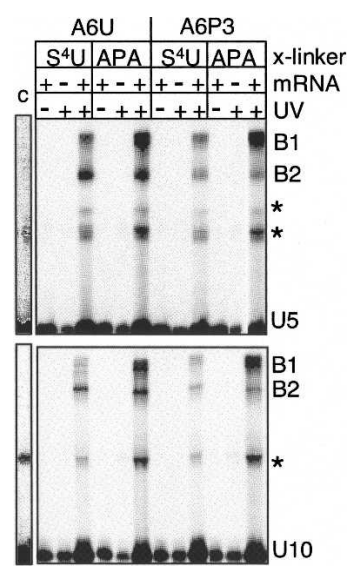

FIGURE 2. $\mathrm{A} 6 \mathrm{U}$ and $\mathrm{A} 6 \mathrm{P} 3$ cross-links with $5^{\prime}{ }^{32} \mathrm{P}-$ labeled gA6-14$\mathrm{U} 5$, (U5) (top panel) or gA6-14-U10 (U10) (bottom). U5 and U10 indicate that the position of the cross-linking agent $\left(\mathrm{S}^{4} \mathrm{U}\right.$ or APA) was at the 5th or 10th uridylate, respectively, in the U-tail. B1 and B2 are two populations of cross-linked molecules. Asterisks represent intragRNA cross-links that were also present in the control lane (no mRNA) when the gel was overexposed (representative lane, labeled C) or were not consistently observed in all experiments. Due to limited amounts of sample, only $1 / 10$ of the cross-linked molecules were used in the control lanes (no mRNA and no UV lanes). 
identified cross-links, as recommended by Sontheimer (1994). APA augmented both the cross-linking and RT halting efficiency and facilitated subsequent mapping; however, it cross-linked to a broad number of nucleotides. With $\mathrm{S}^{4} \mathrm{U}$ alone, the percentage of cross-linked molecules was low, and they were more difficult to map; however, the results were most often supportive, overlapping with the APA sites. A summary of the mapped cross-linked sites is shown in Figure 3.

Identified cross-link sites in B1, with or without APA, generally located upstream of the first few editing sites. For both A6U and A6P3, the strongest mapped cross-link sites were complementary for both the U5 and U10 thio placements; U5 cross-linked most strongly with nucleotides 2933 and U10 with 23-28. In the absence of APA, the gRNA with the $S^{4} U$ in the $U 5$ position did cross-link to additional sites closer to the ABS. Strong U5-S ${ }^{4} \mathrm{U}$ cross-links were observed at positions 37 and 39 within the unedited mRNA, and weak, but distinct cross-links were observed at positions 38 and 39 within the partially edited substrate. Although both of these sites are predicted to be within a helical region in our model, they were located at the end of a stem and may reflect the propensity for $S^{4} U$ to prefer unpaired bases. With the addition of APA, gA6-14-U10 also induced weak but distinct cross-links at nucleotides 7 and 8 in both the unedited and partially edited substrates. This cross-link site was not identified with gA6-14-U5 through primer extension; however, the RNase $\mathrm{H}$ analyses (presented below) suggest that similar cross-links did exist when the APA was in U5. Unexpectedly, when the A6P3 substrate was paired with either the U5 or U10 thiomodified gRNA, distinct cross-links were also detected within the anchor helix at nucleotides 51-54. This 51-54 cross-link site was not identified in A6U through primer extension; however, the RNase $\mathrm{H}$ analyses (presented below) suggest that similar cross-links did exist in the unedited substrate.

U-tail cross-linking sites within the B2 complexes were much more difficult to map by primer extension. Analyses of $\mathrm{A} 6 \mathrm{U}$ and $\mathrm{A} 6 \mathrm{P} 3$ cross-linked to gA6-14-U5 showed no distinct transcription stops. Analyses of A6U and A6P3 cross-linked to gA6-14-U10 however, indicated cross-linking to nucleotides located within or just downstream from the ABS. This suggests that a tertiary folding may place the U-tail helix closer to the anchor helix.

As previously reported, reverse transcriptase has difficulty transcribing through specific residues within the A6 mRNA sequence (Leung and Koslowsky 1999). The

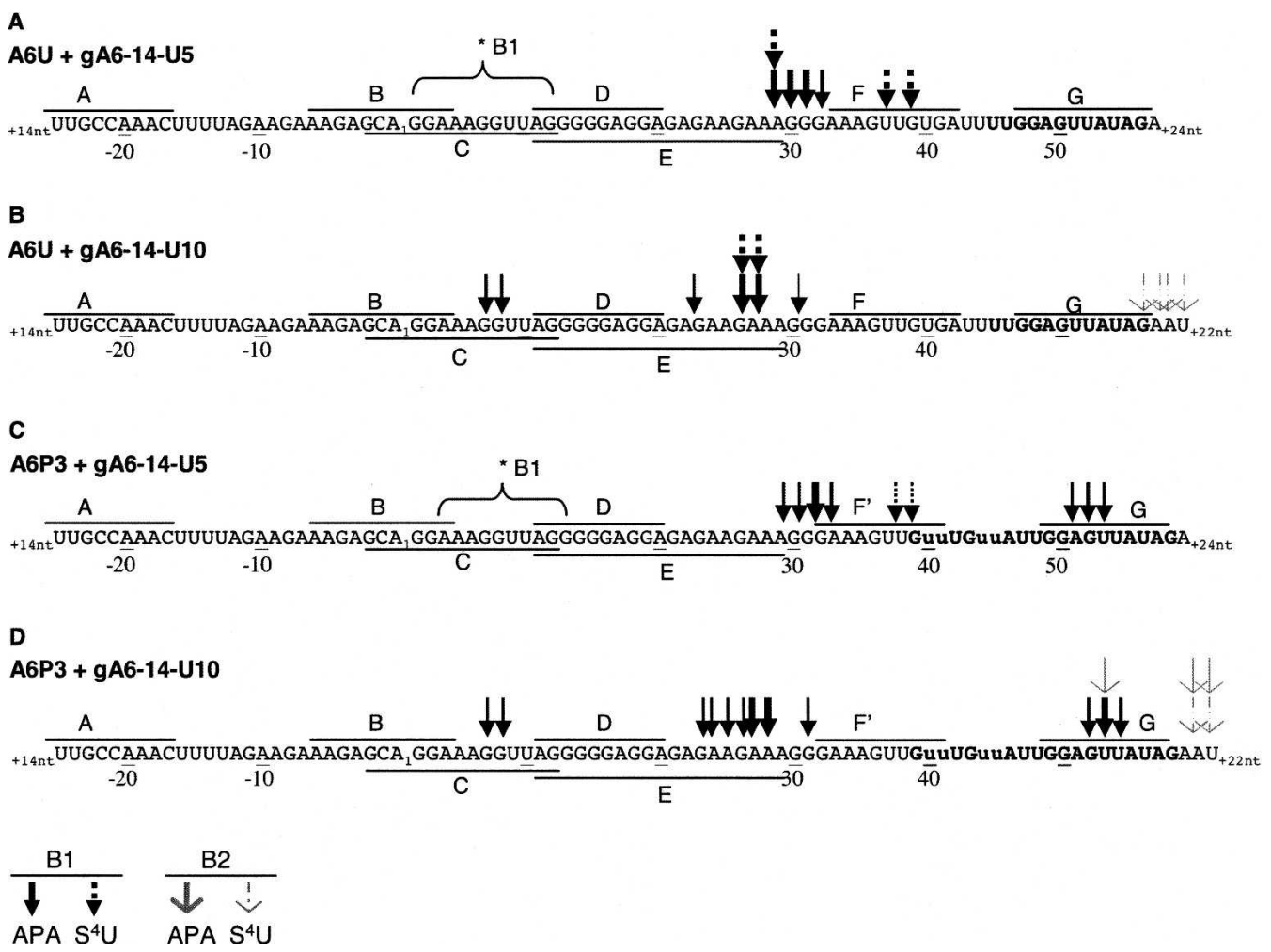

FIGURE 3. $(A-D)$ Mapped cross-link sites within A6U and A6P3 cross-linked to gA6-14-U5 or gA6-14-U10 (gRNA sequence is not shown). Arrows indicate sites determined through primer extension and confirmed through RNase $\mathrm{H}$ analysis. Arrow thickness correlates with intensity of the RT stop. Lines above and below the sequence labeled A to G indicate the position of each ODN used in RNase $\mathrm{H}$ assays. Sequence numbering is according to Figure 1. ${ }^{*} \mathrm{~B} 1$ indicates approximate position of cross-link site detected by RNase H assay only. B1 (solid head arrows) and B2 (open head arrows) are cross-link populations shown in Figure 2. 
$A_{3} G_{3} A_{3}$ sequence located at nucleotides 27-35 appears to be particularly difficult. Since the majority of our mapped cross-link sites fell within this region, RNase $\mathrm{H}$ mapping was used to confirm their presence. While RNase $\mathrm{H}$ mapping is less precise than $\mathrm{RT}$, it can confirm the existence of a cross-link within a small sequence between two oligodeoxynucleotides (ODNs) (Sontheimer 1994). In addition, the sensitivity of the RNase $\mathrm{H}$ assay allows the detection of low-population cross-links. Our assays involved hybridizing the radiolabeled cross-linked mRNA/ gRNA molecules to a combination of 7 ODNs (Fig. 3, A-G) and digesting with RNase $\mathrm{H}$. The ODN positions within the mRNAs are shown in Figure 3 and representative RNase $\mathrm{H}$ digests are in Figure 4. Because the radiolabel is carried within the gRNA, only fragments containing a cross-link are visible.

A

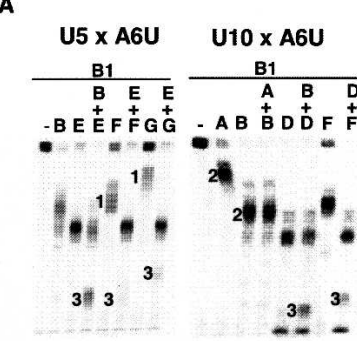

B

C

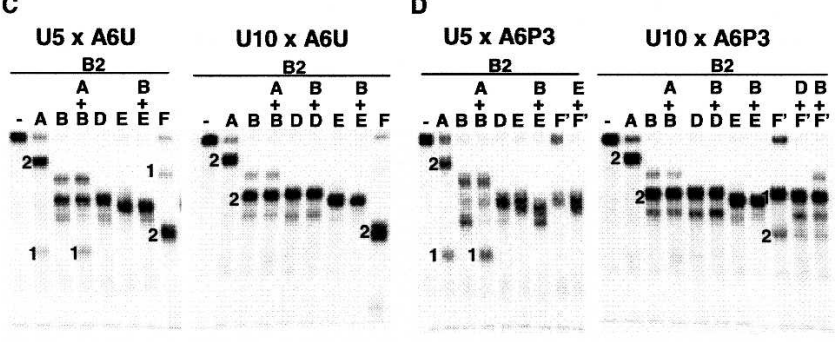

Schematics of possible RNase $\mathrm{H}$ digestion products when using 1 or 2 ODNs (produc migration vary according to ODN position and RNA structure)

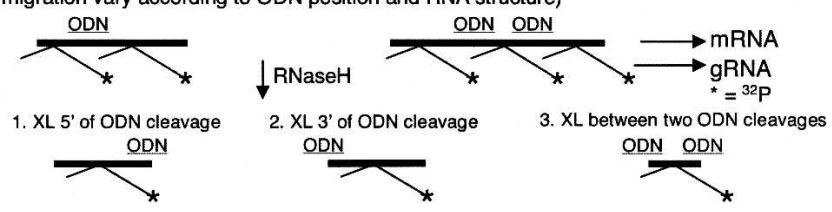

FIGURE 4. RNase $\mathrm{H}$ assays confirming cross-link sites for $\mathrm{B} 1$ and $\mathrm{B} 2$ populations of $\mathrm{A} 6 \mathrm{U}$ and $\mathrm{A} 6 \mathrm{P} 3$ cross-linked to gA6-14-U5 (U5) or gA6-14-U10 (U10) from Figure 2. Top panels are B1 cross-links with A6U $(A)$ and A6P3 $(B)$. Bottom panels are B2 cross-links with A6U $(C)$ and A6P3 (D). (A-G) ODNs complementary to a specific sequence within the mRNA, specified in Figure 3. (Lanes labeled with a minus sign) control without ODN. Note incomplete digestion with ODNs F, $\mathrm{G}, \mathrm{A}$, and $\mathrm{E}$, due to poor hybridization to mRNA, probably because of potential interfering cross-links or anchor helix formation. This generated less digestion product and therefore, bands 3 are often light. Numbers on the left side of bands correlate with digestion products shown in the schematic. Light bands at the bottom of each gel lane are radioactively labeled gRNA that detached from the mRNA during the experimental procedure.
Using the RNase $\mathrm{H}$ technique, the presence of strong $\mathrm{B} 1$ cross-links between nucleotides 22 and 39 within A6U and A6P3 substrates were confirmed (Fig. 4A,B). RNase $\mathrm{H}$ digestions using one ODN at a time confirmed the presence of cross-links downstream from $\mathrm{E}$ and upstream of $\mathrm{F}\left(\mathrm{F}^{\prime}\right)$ (Fig. 4A,B; data not shown). In addition, digestion with ODNs $\mathrm{B}+\mathrm{E}$ and $\mathrm{B}+\mathrm{D}$ resulted in the formation of two labeled products; one the same size as with $\mathrm{E}$ alone (crosslinks found downstream from E) and one small product (cross-links found between $\mathrm{B}$ and $\mathrm{E}$ or D). This confirms the RT cross-links at nucleotides 7 and 8 for gA6-14-U10 $\mathrm{x}$ $\mathrm{A} 6 \mathrm{U}$ or $\mathrm{A} 6 \mathrm{P} 3$ and suggests that cross-links at the same site, though not detected by RT, were also present with gA6-14$\mathrm{U} 5 \mathrm{x}$ A6U and A6P3 (Figs. 3, 4A,B, asterisks). It may be that these sites were not detected using reverse transcriptase in the U5 cross-links due to the purine-rich nature of this region. Incomplete digestion of the mRNA using ODNs $F$ $\left(\mathrm{F}^{\prime}\right)$ and $\mathrm{G}$ make double digests using these ODNs more difficult to interpret because the intensity of the product band does not correlate with quantity of cross-linked molecules. Incomplete digestion is due to impaired hybridization of these ODNs, because the corresponding mRNA site coincides either with the binding site for the gRNA anchor or with cross-link sites. Nonetheless, digestions of A6U cross-links with $\mathrm{E}+\mathrm{F}, \mathrm{E}+\mathrm{G}$, or $\mathrm{D}+\mathrm{F}$ generated two detectable products: one population corresponding to the incomplete digestions (not digested by F or G) and a small product (band 3, cross-links located between the two ODNs), confirming once again the cross-links within nucleotides 22-39. Double digestions using the $F^{\prime}$ and $G$ ODNs for the A6P3 cross-links were much more difficult to interpret. Digestion with $\mathrm{F}^{\prime}$ alone generated a product that migrated either slightly slower or even with the D and $\mathrm{E}$ ODN-generated products, suggesting that most of the cross-links were upstream of $\mathrm{F}^{\prime}$. No smaller product was observed, so we could not confirm the RT identified crosslinks downstream from $\mathrm{F}^{\prime}$. In addition, double digests with ODNs $\mathrm{E}$ and either $\mathrm{F}^{\prime}$ or $\mathrm{G}$ were not conclusive (data not shown).

RNase $\mathrm{H}$ analyses of the gA6-14-U5 B2 cross-links indicated that this population also contained cross-links in at least two distinct areas (Fig. 4C,D). Digestion of these cross-links with ODN A gave rise to two products, indicating that the cross-links were located both upstream of and downstream from A for both $\mathrm{A} 6 \mathrm{U}$ and A6P3. Digestion with multiple ODN combinations $(\mathrm{A}+\mathrm{C}, \mathrm{C}+\mathrm{E}$, $\mathrm{E}+\mathrm{F}, \mathrm{E}+\mathrm{G}$, and $\mathrm{D}+\mathrm{G}$ [data not shown] and $\mathrm{A}+\mathrm{B}, \mathrm{B}+\mathrm{E}$, $\mathrm{B}+\mathrm{D}, \mathrm{B}+\mathrm{F}^{\prime}$, and $\left.\mathrm{D}+\mathrm{F}^{\prime}\right)$ excluded the presence of cross-links between ODNs $A$ and $F\left(F^{\prime}\right)$, indicating that one cross-link population was upstream of $\mathrm{A}$ and the second population located downstream from the ABS. Digestion of A6U x gA6-14-U5 with G alone (data not shown) and F alone generated two mobility products, supporting the finding of two cross-link populations. Digestion with D or E alone probably gave two fragments of similar size that overlapped 
in Figure 4C. Unfortunately, digestion of A6P3 x gA6-14U5 (B2) with ODN $\mathrm{F}^{\prime}$ was also incomplete. However, double digestion with $\mathrm{ODNs} \mathrm{B}+\mathrm{E}$ and $\mathrm{E}+\mathrm{F}^{\prime}$ generated only one fragment, and $\mathrm{A}+\mathrm{B}$ generated fragments similar to $\mathrm{A}$ and $\mathrm{B}$ alone, confirming that the cross-links were located upstream of $\mathrm{A}$ and downstream from $\mathrm{F}^{\prime}$.

Analyses of the gA6-14-U10 B2 cross-links (Figs. 3, 4C,D) were similar to those observed for U5 with one major exception: Cross-links upstream of A were not detected (Fig. 4C,D, note absence of band 1 when A was used alone). Again, the analyses were difficult because we saw little difference in mobility with the single digests using ODN C (data not shown), B, D, or E. However, multiple double digests using these ODNs indicate that no crosslinks exist between ODNs A and E. Digestion of gA6-14U10 x A6U (B2) with ODN F did generate one fragment of faster mobility (compare with F alone in gA6-14-U5 x A6U, $\mathrm{B} 2$ ), indicating that the cross-link is located downstream from F. In contrast, digestion of gA6-14-U10 x A6P3 with ODN $F^{\prime}$ generated two fragments, suggesting that crosslinks did exist both upstream of and downstream from $\mathrm{F}^{\prime}$. Double digests with $\mathrm{A}+\mathrm{B}, \mathrm{B}+\mathrm{D}, \mathrm{B}+\mathrm{E}, \mathrm{D}+\mathrm{F}^{\prime}$, and $\mathrm{B}+\mathrm{F}^{\prime}$ did not generate any specific fragment (band 3 ) that could confirm a cross-link between A and F.

In summary, the cross-linking experiments generated two populations of mRNA/gRNA complexes, B1 and B2. Using both reverse transcriptase and RNase $\mathrm{H}$ analyses, B1 cross-linked sites were localized to a region upstream of the first editing site. The mapped cross-linked sites for the U5 or U10 modified gA6-14 were complementary, indicating that the U-tail interaction is strongest with nucleotides 25-32 within both A6U and A6P3. The identification of multiple cross-links within a small range of nucleotides suggests a flexible interaction of the U-tail with the mRNA in this region. In addition, for a population of molecules, the U-tail interaction was farther upstream, with cross-links detected at nucleotides 7-8. For both A6U and A6P3, the cross-linking patterns were almost identical, indicating that the $\mathrm{U}$-tail is interacting with the same region. In contrast, the B2 cross-link sites were difficult to map by RT, and RNase $H$ analyses suggest that most of the cross-links were downstream from the ABS. A small population of the gA614-U5 modified guide RNA did cross-link to nucleotides located near the $5^{\prime}$-end of the mRNA. These upstream cross-links may be a product of $5^{\prime}$-end mRNA folding close to the U-tail. The mapped B2 sites downstream from the ABS indicate potential tertiary folding of the U-tail and anchor helices close to each other.

\section{Solution structure probing}

Enzymatic and chemical structure probing in solution are used to study the existence and strength of RNA structures under nearly physiological conditions (Cech et al. 1983; Ehresmann et al. 1987; Knapp 1989; Leung and Koslowsky 2001a). In mRNA/gRNA bimolecular structures, the anchor helix is presumed to form due to the complementarity of the mRNA ABS, immediately $3^{\prime}$ of the editing site, and gRNA anchor, at the gRNA's 5' -end (Blum et al. 1990). However, the weak binding affinity of some mRNA/ gRNA pairs allows for the presence of unpaired RNAs, preventing accurate structure probing. To counteract this problem, the use of cross-linked RNAs facilitated base pairing of the anchor region and assured folding of the two molecules together (Leung and Koslowsky 2001a; Yu and Koslowsky 2006). 5'-Cross-linked RNAs have been shown to support editosome assembly (Leung and Koslowsky 2001a). Incubation of cross-linked substrates in editing active mitochondrial fractions results in accurate gRNA-directed cleavage. In addition, at sites of U-deletion (the crosslinked A6U and A6P3 substrates), U-specific exonuclease activity on the $5^{\prime}$ cleavage products was observed (Leung and Koslowsky 2001a). This indicates that the editing complex interacts and assembles correctly on the crosslinked RNAs and that structures determined utilizing these molecules are biologically relevant. Determination of the affinity constant for the A6 pair indicated that gA6-14 has a high affinity for its target mRNA (Koslowsky et al. 2004), suggesting that cross-linking of the two molecules might not be necessary. In this study, we conducted solution structure probing experiments using both cross-linked and non-cross-linked A6 RNA complexes. Direct comparisons showed no differences in the digestion patterns, indicating that simple hybridization was sufficient for generating complexes stable enough for solution structure probing. Eliminating the cross-linking step also allowed us to probe the RNA structures using both $5^{\prime}$ - and $3^{\prime}$-end-labeled molecules. In addition, to facilitate the probing, the mRNAs were shortened at their $5^{\prime}$-ends (sequence that does not interact with the U-tail), based on our U-tail cross-linking results described above. Again, shortening of the A6 substrate at its $5^{\prime}$-end has no effect on its ability to undergo editing when incubated with glycerol gradient purified editosomes (Burgess et al. 1999; Cruz-Reyes et al. 2001; Lawson et al. 2001; Igo et al. 2002; Cifuentes-Rojas et al. 2005; data not shown).

The solution structure probing experimental approach was similar for all treatments. The RNA was first ${ }^{32} \mathrm{P}$-end labeled (either mRNA or gRNA, one at a time, at the $5^{\prime}$ - or $3^{\prime}$-end), gel purified, denatured and then renatured alone or in the presence of its interacting partner under native conditions $\left(10 \mathrm{mM} \mathrm{MgCl}_{2}, 100 \mathrm{mM} \mathrm{KCl,} 10 \mathrm{mM}\right.$ Tris- $\mathrm{HCl}$ at $\mathrm{pH} 7.5$ at $27^{\circ} \mathrm{C}$ for $3 \mathrm{~h}$ ). To assess single-stranded (ss) regions we utilized RNase T1 (specifically cleaves guanines), RNase T2 and Mung Bean (MB) (preference for adenines) (Knapp 1989), and the chemical diethyl pyrocarbonate (DEPC) to modify the N7 position of unstacked adenines and guanines (Peattie 1979; Ehresmann et al. 1987). The double stranded (ds) or stacked areas were tested with cobra venom RNase V1 (Lockard and Kumar 
1981). Representative examples of gels used to separate the digestion products are shown in Figure 5.

gRNA structure (gA6-14, gA6-14sU, and gA6-14-C6)

(Figs. 5B, 6A)

The secondary structure for gA6-14 and four other gRNAs has been previously determined and proposed to be a single or a double stem-loop separated by single-stranded nucleotides and single-stranded U-tail (Schmid et al. 1995; Hermann et al. 1997; Golden and Hajduk 2006; Yu and Koslowsky 2006). The finding of a common conformation among gRNAs of distinct sequences was suggestive of a binding site for specific proteins that could facilitate editosome assembly (Muller and Goringer 2002; Schumacher et al. 2006). Our goal was to find the secondary structure of gA614 in a binary complex with the mRNA and determine how the U-tail might influence the structure. As a control, we additionally obtained the gA6-14 structure in solution. While our conditions and sequence were slightly different from Schmid et al. (1995), we also observed two stemloops in gA6-14. Accessibility to single-stranded specific enzymes within nucleotides $6-8$ and to the double-stranded specific V1 enzyme on nucleotides 11-13 defined a small stem-loop, which we call stem-loop I (SL I), present within all three gRNA constructs. SL I included the 5 '-end of the anchor within the loop. Stem-loop II was larger, formed by the guiding nucleotides, and persisted even after ablation of the U-tail, in gA6-14sU. Digestion by the $\mathrm{V} 1$ enzyme and protection against single-stranded specific probes at nucleotides 23-29 and 38-45 defined the stem of SL II within gA6-14 and gA6-14sU. The apical loop of SL II was highly accessible to single-stranded specific probes, confirming their unpaired nature. The substitution of 6 U's from the U-tail by $6 \mathrm{C}$ 's in gA6-14-C6 did change the digestion/modification pattern within SL II, forming two alternate stem-loops (stemloop IIa and b, Fig. 6A). SL IIa involved 3 base pairs (bp) (nucleotides 14-16 and 22-24) confirmed by V1 digestions at nucleotides 14, 23, and 24 and mfold predictions (Walter et al. 1994; Zuker 2003). The larger SL IIb involved the C6-tail and was confirmed by the presence of V1 digestion within both sides of the stem (nucleotides 32-44 and 48-60). Weak accessibility by single-stranded specific enzymes and DEPC within the stem is explained by the presence of several singlenucleotide mismatches that destabilize the helix. Nonetheless, this gA6-14-C6 seems to be thermodynamically more stable than the parental gRNA.

mRNA structure (A6U and A6P3) (Figs. 5A, 6A)

The $3^{\prime}$-end of the unedited A6 mRNA is purine rich, thus predicted to be mostly unstructured (Koslowsky et al. 2004). Solution structure probing of A6U alone indicated that its most stable structure involves the formation of a single (8-
$10 \mathrm{bp)} \mathrm{stem} \mathrm{with} \mathrm{an} \mathrm{11-nt} \mathrm{loop.} \mathrm{V1} \mathrm{cleavages} \mathrm{within} \mathrm{a} \mathrm{few}$ loop nucleotides suggest that they may interact or stack. Note that the ABS is mostly contained within the terminal loop. When the mRNA is partially edited through three sites (A6P3) the 11-nt terminal loop was maintained. However, the sequence changes associated with RNA editing introduced new base pairings within the stem region.

mRNA/gRNA structure (Figs. 5, 6B)

The secondary structure in solution for 6 mRNA/gRNA pairs (A6U and A6P3 with gA6-14, gA6-14sU, and gA6-14C6) are described below, by motif, starting with the anchor helix, then the U-tail helix, the gRNA stem-loop, and lastly the mRNA junction at the intersection of the three helices.

Anchor helix-A6U and A6P3 hybridized to gA6-14, gA614sU, and gA6-14-C6. The anchor helix within A6U/gA614 involves formation of 12 contiguous base pairs formed between the ABS of the mRNA and the anchor of the gRNA. Structure probing after cross-linking or hybridization indicates that both the ABS and the gRNA anchor are protected from single-stranded nucleases, confirming proper binding and formation of the recognition helix. When the mRNA was not cross-linked to the gRNA, its $3^{\prime}$ end was more sensitive to single-stranded probes as opposed to the cross-linked molecules. This higher sensitivity was expected and due to termini breathing because the molecules were not covalently linked. The sensitivity was more noticeable and extended throughout the ABS when $\mathrm{A} 6 \mathrm{U}$ was paired with gA6-14sU, suggesting that the presence of a gRNA U-tail increases the stability of the $3^{\prime}$ anchor helix. Anchor helix formation was confirmed by RNase V1, with V1-dependent cleavages observed at both ends of the duplex. V1 digestion at the helix ends was expected considering that V1 does not digest the entire extension of a duplex (Lockard and Kumar 1981). V1 requires a minimum of four to six sugar phosphate residues within a helix to bind and cleave the phosphates on either strand (Lowman and Draper 1986). A similar V1 digestion pattern, cleaving at both ends of a helix, has been previously reported for the $\mathrm{CYb}$ anchor helix (Yu and Koslowsky 2006).

Editing of the first three sites in A6P3 extends the anchor helix by 8 additional base pairs. Similar to A6U, the $3^{\prime}$-end of A6P3 ABS was lightly cleaved by single-strand specific probes when the complex was not cross-linked. Nonetheless, both sides of the helix were protected from cleavage by ss specific probes. In contrast to $\mathrm{A} 6 \mathrm{U}$, an increased sensitivity to the ss specific probes was not observed when A6P3 was paired with gA6-14sU, reflecting the increased stability introduced by the additional base pairs. Again, the V1 digestion pattern was complementary to the other probes.

U-tail helix-A6U and A6P3 hybridized to gA6-14 and gA614-C6. UV cross-linking experiments indicate that A6/gA6-14 

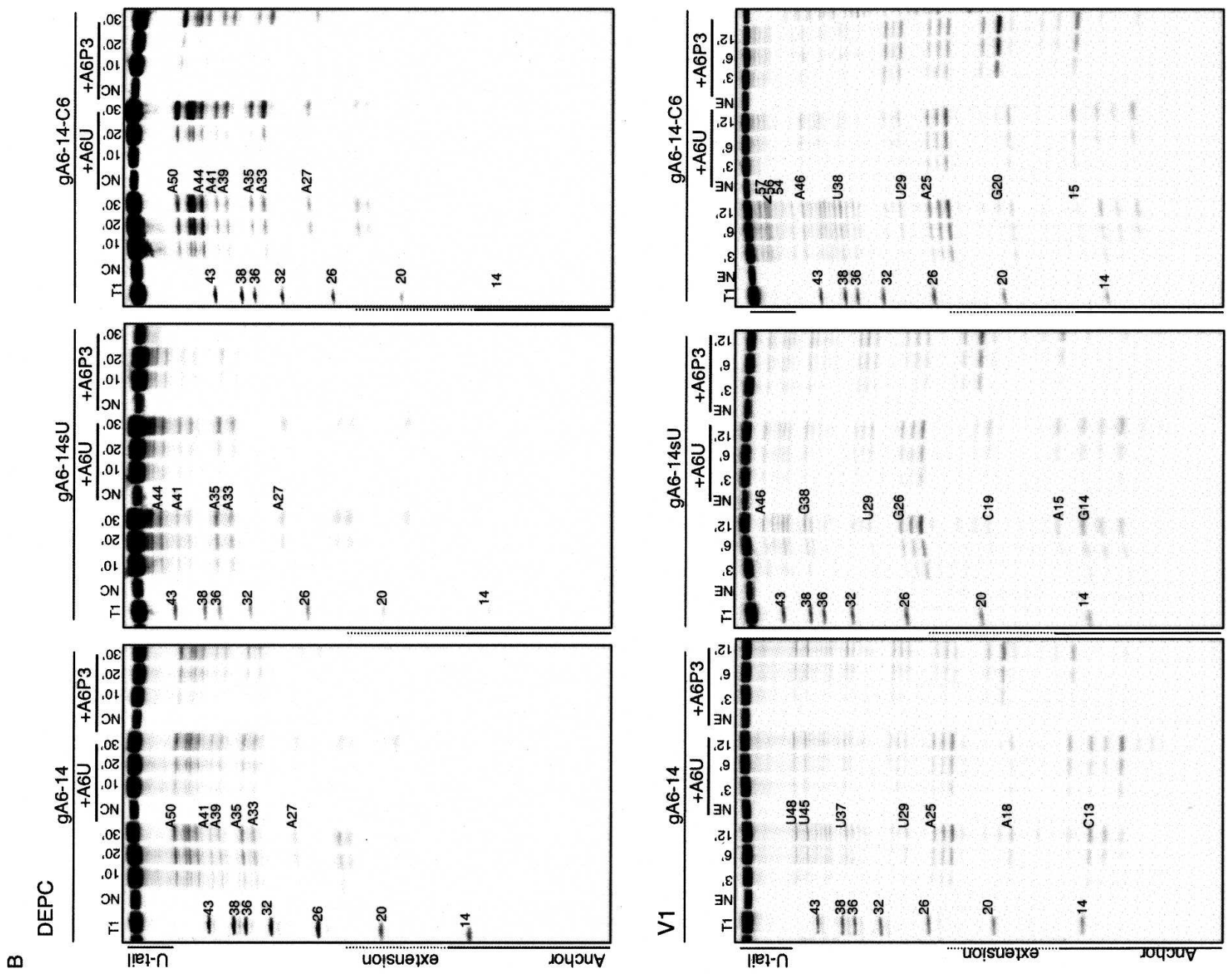

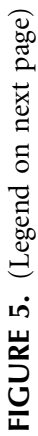
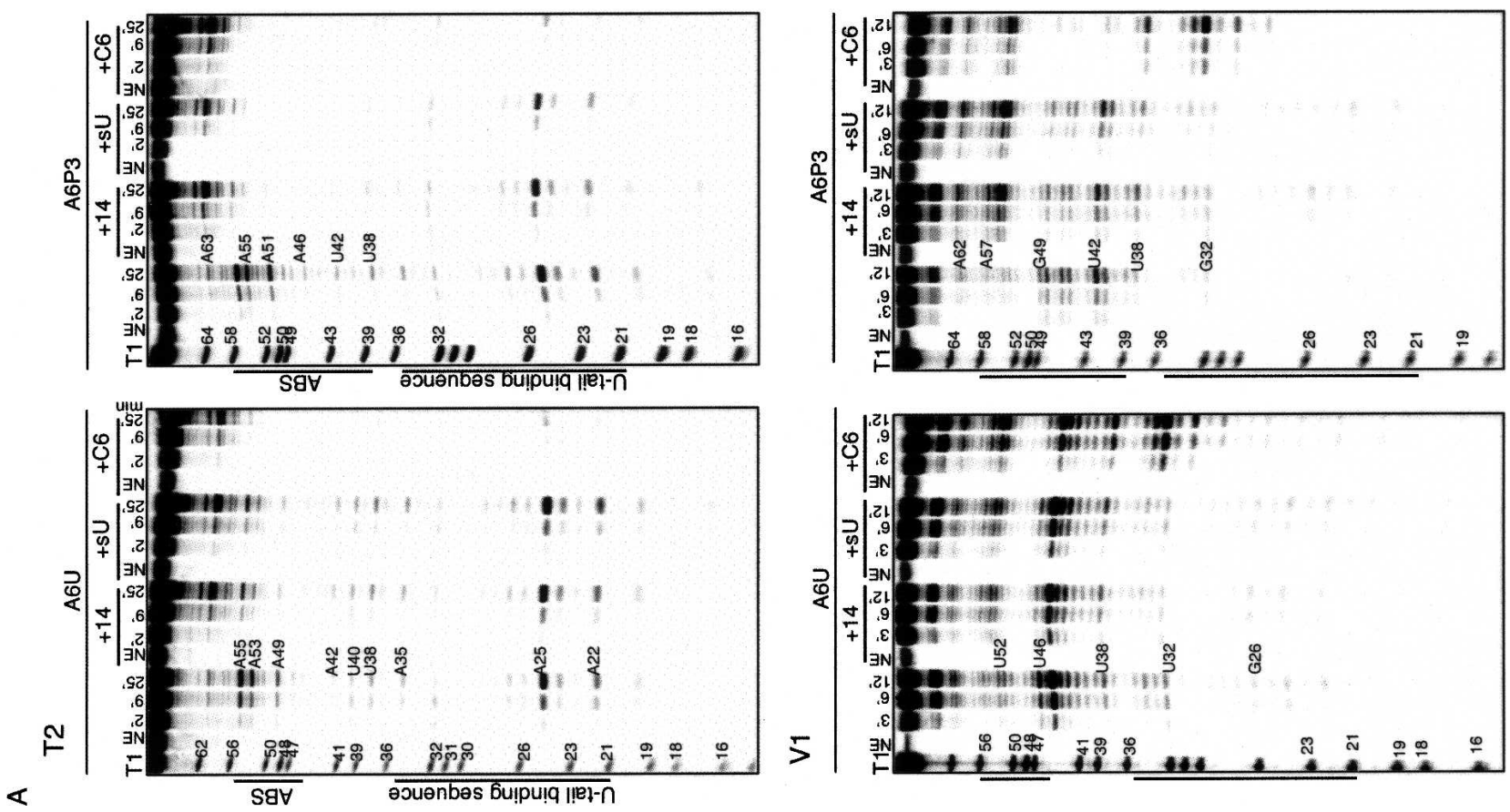


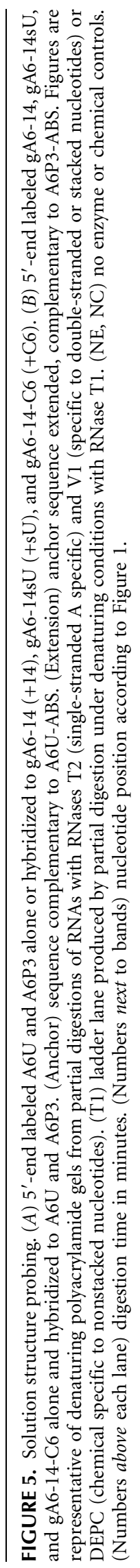


A

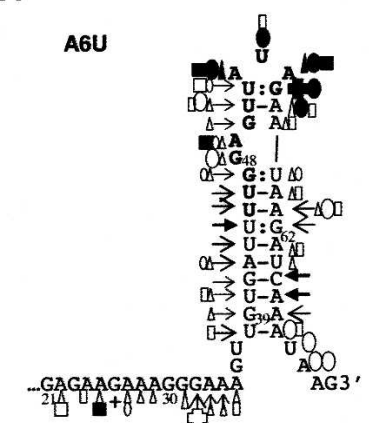

gA6-14

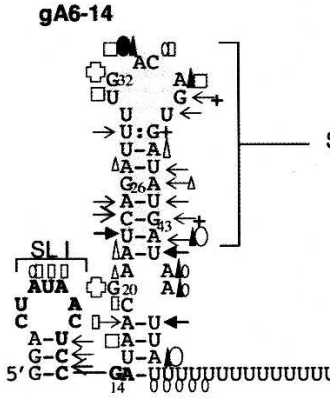

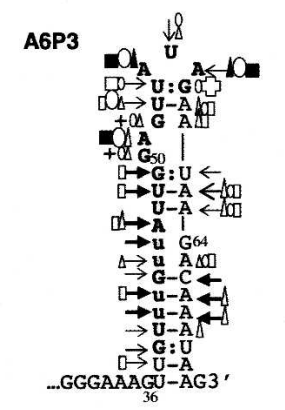

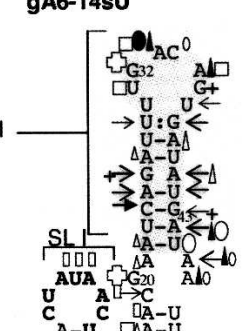

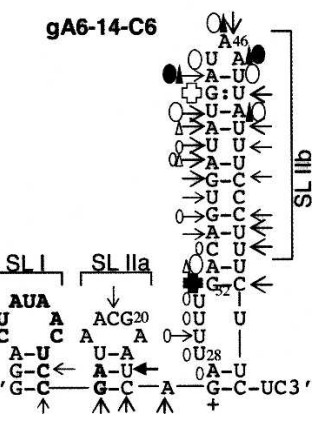

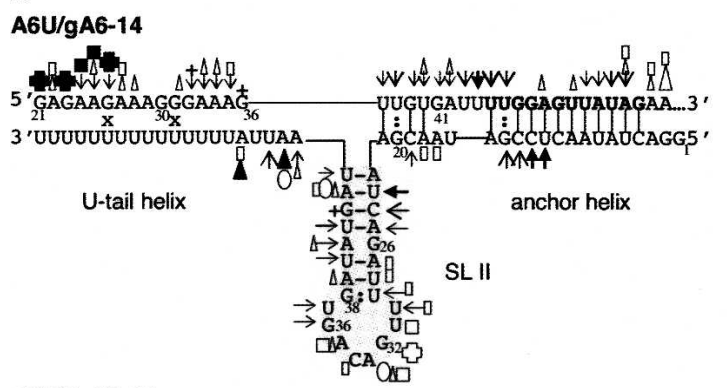

resonentin

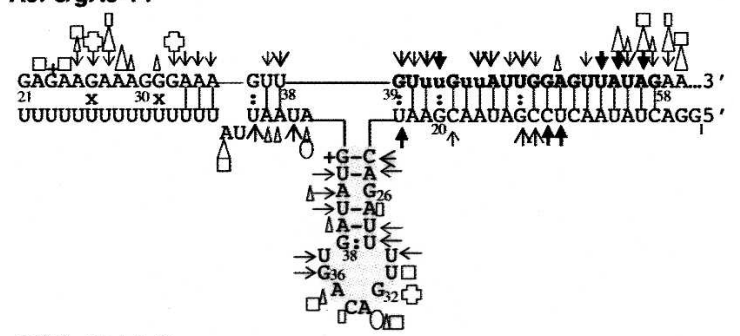

A6U/gA6-14sU

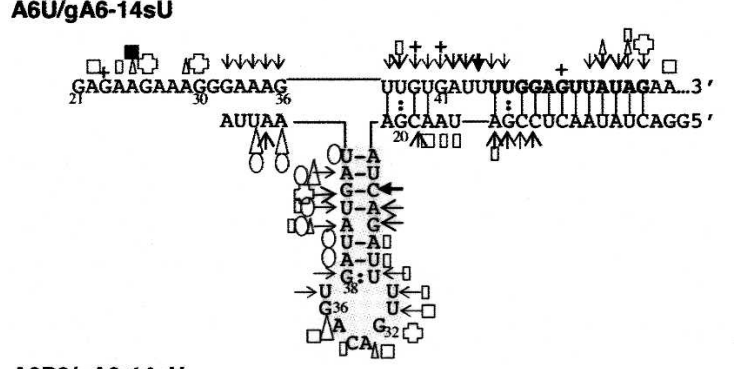

A6P3/gA6-14sU

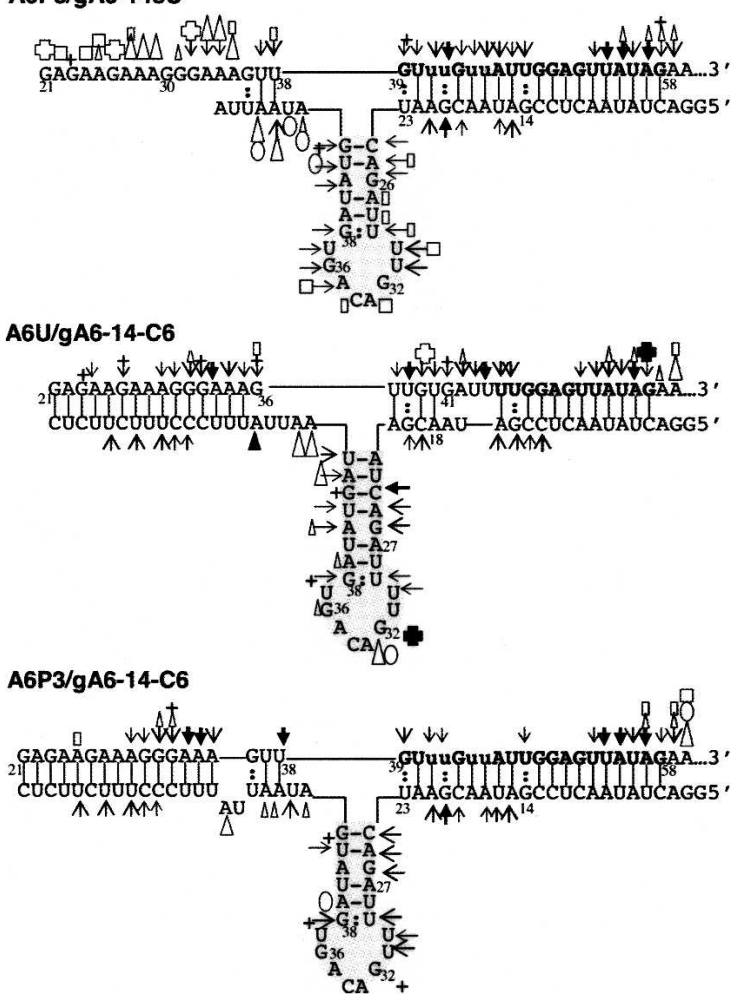

FIGURE 6. (Legend on next page) 
complexes form a U-tail helix involving the gRNA U-tail and the purine region $\mathrm{G} 21$ to $\mathrm{A} 35$ within $\mathrm{A} 6 \mathrm{U}$ and A6P3. While the strongest cross-links were mapped to nucleotides 29-31 for U5 and 26-28 for U10, a number of cross-links were identified, suggesting that the U-tail interaction is dynamic within this region. Solution structure probing indicated that most of this region was susceptible to single-strand specific probes, and the few V1 cleavages were inconsistent and light. This indicates that the U-tail forms a relatively unstable, flexible duplex with the purine-rich region. Duplex instability has been associated with G:U wobble base pairs (Freier et al. 1986) that are unlikely to stack (Auron et al. 1982) and therefore are not recognized by RNase V1. The enhanced gA614-C6 introduces $6 \mathrm{G}: \mathrm{C}$ base pairs that strengthen binding, and this allowed structure probing of the U-tail helix. Decreasing the number of G:U base pairs and increasing the G:C content reduced the number of sites accessible to singlestranded probes and increased V1 products, confirming stable helix formation. Stabilizing the U-tail interaction also seemed to stabilize the gRNA stem-loop, described below.

gRNA stem-loop II (SL II)-A6U and A6P3 hybridized to gA614, gA6-14sU, and gA6-14-C6. As described above, gA6-14 alone forms a stable stem-loop (SL II) that involves the guiding region nucleotides (Fig. 6A). Similar to the cytochrome b interaction with gCYb-558 (Yu and Koslowsky 2006) this stem-loop appears to be maintained during the initial interactions with the mRNA. V1 digestions from U23 to U29 and between G38-U45 (bases within the stem) were detected in gA6-14 alone as well as when the gRNA was cross-linked or hybridized to both A6U and A6P3. The apical loop within gA6-14, formed with both mRNA pairings, was readily accessible to single-stranded probes. RNase V1 lightly cleaved at the loop nucleotides (U30-31 and G36-U37) near the closing nucleotides. This V1 pattern of loop digestion has been previously observed and can be caused by a number of conditions, which include overcutting the terminal ends of a double-stranded region (Auron et al. 1982), higher order structure in the loop, like stacking of loop nucleotides with the stem (Krol et al. 1990), Watson-Crick or wobble hydrogen bonds between loop bases (Burkard et al. 1999), or tertiary interactions (Lockard and Kumar 1981). Editing of A6U through three editing sites (A6P3) does disrupt the first 2 bp of the gRNA stem-loop II. However, the loss of these 2 bp did not destabilize the rest of the gRNA stem-loop structure.
Light cleavage by single-stranded probes was observed within the gRNA stem region, most likely due to some destabilization caused by the single A:G mismatch (Figs. $5 \mathrm{~B}, 6 \mathrm{~B})$. However, the stability of the stem also appears to be influenced by the presence of the upstream U-tail helix. Deletion of the U-tail (gA6-14sU) causes an increased susceptibility of the $3^{\prime}$ side of the stem to ss specific probes. In addition, strengthening of the U-tail interaction by using the modified gA6-14-C6 decreased the intensity and the number of sites available for the ss specific probes. This suggests that the U-tail not only stabilizes the anchor helix but also the gRNA stem-loop II. For the A6P3 pairing, RNase V1 cleavages were observed at the junction between the anchor helix and gRNA stem-loop, suggesting continuity between both helices. Continuous V1 digestion at RNA junctions, indicating helical stacking, has been described in other RNAs such as tRNAs, U1 snRNA, and cucumber mosaic virus satellite RNA (Auron et al. 1982; Lowman and Draper 1986; Krol et al. 1990; Bernal and Garcia-Arenal 1997; Lescoute and Westhof 2006). While this V1 pattern was not observed in the A6U/gA6-14 pair, we did observe an absence of single-strand specific probe accessibility, which is also suggestive of continuous doublestranded stacking of two helices.

Junction-A6U hybridized to gA6-14, gA6-14s $\mathrm{U}$, and gA6-14C6. The connecting sequence mRNA $5^{\prime}-U_{U G U G} A_{41} \mathrm{AUU}_{44^{-}}$ $3^{\prime}$, partially paired with gRNA $3^{\prime}-\mathrm{AG}_{20} \mathrm{CAAU}_{16^{-}} 5^{\prime}$, forms an asymmetrical internal loop at the $5^{\prime}$-end (mRNA orientation) of the anchor helix, next to the SL II and the U-tail helix (Figs. 5, 6B). The models suggest that there are nucleotides within this asymmetrical loop that are not base paired; however, when A6U/gA6-14 was analyzed, these junction nucleotides were not digested by ss specific probes, but were susceptible to RNase V1. V1 cleaved the $5^{\prime}$-end of the mRNA ABS, extended through the three first junction nucleotides, and cleaved again at the 4-bp stem. While this $\mathrm{V} 1$ digestion pattern was maintained when $\mathrm{A} 6 \mathrm{U}$ was folded in the presence of gA6-14sU and gA6-14-C6, the mRNA nucleotides at the junction appeared to be more available to ss specific probes. The strongest V1 cleavages were at the bonds between nucleotides 42 and 44 within the $4 \times 6$ internal loop, indicating that these loop nucleotides could be interacting with the opposing gRNA nucleotides or stacking between the two stems. On the gRNA, V1 cleaved at C19-G20, confirming the 4-bp stem formation. V1 only

FIGURE 6. Secondary structure models for the individual A6 RNAs and mRNA/gRNAs during distinct stages of editing. ( $A$ ) Individual RNAs, A6U, A6P3, gA6-14, gA6-14sU, and gA6-14-C6. The ABS within the mRNAs and the anchor region within the gRNAs are bolded. The anchor extends to nucleotide 23 when the gRNAs are paired with A6P3. Stem-loops (SL) are indicated next to gRNAs. In gray is SL II, conserved in many gRNA species. (B) mRNA/gRNA complexes, as indicated: A6U and A6P3 with gA6-14, gA6-14sU, and gA6-14-C6. The structures were obtained with a combination of data obtained from cross-linking analysis $(x)$ (mRNA/gRNA pairs only), computer algorithm, and solution structure probing using five different enzymes or chemical. RNase V1 $(\rightarrow)$ has specificity to double-stranded or stacked nucleotides, T1 $(+)$ is specific for single stranded G, T2 $(\square)$ and Mung Bean $(\bigcirc)$ are mostly specific for single-stranded A's, but can also modify other nucleotides. The chemical DEPC $(\Delta)$ is specific for unstacked purines. Symbol size indicates intensity of cleavage and filled symbols indicate the strongest cleavage sites. 
moderately distinguishes stacked single-stranded from base-paired nucleotides (Lowman and Draper 1986). Therefore, it is likely that these junction nucleotides follow the same conformation present in the anchor helix. Analyses using gA6-14-C6, which locks the U-tail in its position, does not change the cleavage patterns at the junction.

Junction-A6P3 hybridized to gA6-14, gA6-14sU, and gA614-C6. The solution structure probing of the junction regions between the anchor helix, SL II, and the U-tail helix for the gRNA interactions with A6P3 are shown in Figures 5 and 6B. The mRNA region (nucleotides 36-38) was not susceptible to cleavage by single-stranded probes and, similar to the unedited mRNA, was cleaved by RNase V1. Again, this suggests that the nucleotides surrounding the next available editing site are in a helical or stacked conformation. Small differences were detected upon deletion of the gRNA U-tail, such as the V1 cleavage sites within the anchor and more intense single-stranded specific digestions at the gRNA 3 '-end (U48-A42). This singlestrand specific digestion in gA6-14sU disappeared when A6P3 was hybridized with the enhanced gA6-14-C6, reinforcing the finding that the U-tail promotes stabilization of the anchor helix and the gRNA stem-loop.

\section{DISCUSSION}

RNA structure promotes editing site specificity in several systems (Connell and Simpson 1998; Koslowsky 2004; Reenan 2005). In kinetoplastids, natural editing sites are flanked by an upstream U-tail helix (Blum et al. 1990; Kable et al. 1996; Leung and Koslowsky 1999) and by a downstream anchor helix (Blum et al. 1990; Byrne et al. 1996; Cruz-Reyes and Sollner-Webb 1996; Kable et al. 1996; Seiwert et al. 1996; Adler and Hajduk 1997). Our results indicate that a third helix, formed by the gRNA, is also present at the junction. We hypothesize that the three helices are part of a core structure that exists in most natural mRNA/gRNA complexes (Leung and Koslowsky 1999, 2001a,b; Yu and Koslowsky 2006). This core threehelical structure has now been confirmed by solution structure probing of the A6/gA6-14 complex (this paper) and the CYb/gCYb-558 complex (Leung and Koslowsky 2001a; Yu and Koslowsky 2006).

In this work, we propose secondary structure models for six A6 mRNA/gRNA pairs obtained by a combination of point constraints coupled with computer folding of primary sequence, plus nuclease and chemical probing. Independently of being unedited (A6U) or partially edited through the first three editing sites (A6P3), the secondary structure for the A6 mRNA/gRNA complex consists of three helices. The anchor helix is a perfect 12 base-paired duplex in A6U/gA6-14 and is extended an additional $8 \mathrm{bp}$ in A6P3/gA6-14. Although our solution structure probing experiments indicate that the U-tail helix is unstable, the cross-linking data and the use of gA6-14-C6 confirmed the $\mathrm{U}$-tail binding site within $\mathrm{A} 6 \mathrm{U}$ and $\mathrm{A} 6 \mathrm{P} 3$ to be $\sim 10$ and $3 \mathrm{nt}$ upstream of the ES, respectively. gA6-14-C6 is a construct developed by Cruz-Reyes et al. (2001) that strengthens U-tail helix affinity and increases editing efficiency by a factor of 4. Cruz-Reyes et al. (2001) observed that U-deletion efficiency in vitro can be further increased when the A6 mRNA/gRNA pair forms a relatively stable anchor and U-tail helices and lacks the third helix (gRNA stem-loop II). The most efficient gRNA construct, D33, was shown to be $>100$ times more efficient than gA6-14$\Delta 16 \mathrm{G}$. D33 is a $26-\mathrm{nt}$ RNA with the gA6-14- $\Delta 16 \mathrm{G}$ anchor, with only 3 C's as guiding nucleotides and with a modified tail ( $3^{\prime}$-CCCUUUCAAUAU- $5^{\prime}$ ) that binds strongly $3 \mathrm{nt}$ upstream of the ES. The native gRNAs did not evolve to have D33 or gA6-14-C6 features because they would not be efficient in vivo since they cannot direct sequential cycles of editing, and the G:C-rich hybrid would be too stable to dissociate. The above work by Cruz-Reyes et al. (2001) and others shows that the position and strength of the U-tail helix formation with the mRNA directly influences editing efficiency (Seiwert et al. 1996; Burgess et al. 1999; Kapushoc and Simpson 1999; Igo et al. 2002; Golden and Hajduk 2006; Cifuentes-Rojas et al. 2007). To evaluate the structural changes caused by distinct U-tails, here we used the parental gA6-14 and gA6-14 without its U-tail (gA6-14sU) and with an enhanced U-tail (gA6-14-C6). We selected gA6-14-C6 because it is identical to the parental gA6-14 in sequence except for the $\mathrm{C}-\mathrm{U}$ substitutions within the $\mathrm{U}$-tail. In fact, gA6-14-C6 generated the same overall bimolecular structure observed with gA6-14, except that the higher stability of the U-tail helix seemed to additionally improve the stability of SL II. The structures generated with gA6-14C6 support the structures obtained with gA6-14. In contrast, deletion of the U-tail (gA6-14sU) decreased the stability within SL II in both the A6U and A6P3 complexes. In addition, deletion of the U-tail also decreased the stability of the anchor helix in the A6U complex. Thus, in addition to confirming the binding site for the U-tail within the unedited and partially edited A6 mRNAs, we found that addition of the U-tail helix stabilizes the other two helices.

In vitro, the gRNA stem-loop has been shown to be dispensable and even inhibitory to U-deletion editing at ES1 in A6 (Seiwert et al. 1996; Cruz-Reyes et al. 2001; Cifuentes-Rojas et al. 2005). However, another study indicates that the gRNA stem-loop structure can be essential for proper editing for some substrates (Golden and Hajduk 2006). In this report, we show that the SL II formed within gA6-14 alone is maintained after gA6-14 annealing with both $\mathrm{A} 6 \mathrm{U}$ and $\mathrm{A} 6 \mathrm{P} 3$, corroborating earlier computer predictions (Leung and Koslowsky 1999). Locking the gA6-14 U-tail into a single position by using the modified gA6-14C6 construct did not affect the formation of SL II in either A6U or A6P3 complexes. Maintenance of SL II going from 
unedited to partially edited A6P3 occurred by simple rearrangements within the guiding region, without displacement of the U-tail. In previous studies with gCYb-558, the gRNA stem-loop was also maintained upon gRNA/ mRNA annealing ( $Y u$ and Koslowsky 2006). In CYb, however, extension of the anchor helix in the partially edited CYbPES3 disrupts base pairs within the original stem-loop structure, with a new stem-loop formed by incorporation of nucleotides from the U-tail. The preservation of the original gRNA stem-loop after annealing with the mRNA, observed in both the A6 and $\mathrm{CYb}$ complexes, suggests that the formation of a three-helical junction is thermodynamically favorable. Furthermore, conservation of the gRNA SL structure through initial stages of editing in both A6 and $\mathrm{CYb}$ mRNA/gRNA complexes supports our hypothesis that a three-helical structure is important for stabilizing the gRNA/mRNA interactions during the initial editing events.

The junction nucleotides between the three helices include the first editing site for A6U (determined ES1) and A6P3 (ES4), which are both deletion sites. The results of the structure probing indicate that ES1 and ES4 have similar features. When both mRNAs were hybridized with gA6-14, gA6-14sU, and gA6-14-C6, the ES and the sequence immediately upstream (6-8 nt) were inaccessible to single-strand specific probes and only accessible to the double-strand- or stacking-specific V1. This suggests that while the scissile base is not involved in Watson-Crick pairing, in agreement with predictions by Seiwert et al. (1996), Cruz-Reyes et al. (2001), and Lawson et al. (2001), it is contained within a highly organized region. This finding was not surprising, because nucleotides in singlestranded areas in a secondary structure are often paired in long-range tertiary interactions, single-strand base stacking, or cross-strand base stacking (Peterson and Feigon 1996; Butcher et al. 1997; Zimmermann et al. 1997; Schroeder et al. 2004; Znosko et al. 2004). Internal loops or bulges are common in RNA structure and create distortions into the geometry of an RNA helix that are often critical for protein recognition (Burkard et al. 1999). For instance, internal loops within $5 \mathrm{~S}$ rRNA have a closed conformation due to several noncanonical interactions that are well suited for protein binding (Westhof et al. 1989; Brunel et al. 1991). Furthermore, the editosome has been shown to directly interact with ES1 and ES2 within the A6 mRNA/D33 complex (Sacharidou et al. 2006; Cifuentes-Rojas et al. 2007). Consistent with this notion, the structural organization observed near A6 ES1 and ES4 in our study may be higher order determinants of editosome binding. Analyses of the unedited CYbU mRNA complexes with gCYb-558 indicate that the nucleotides near ES1 are highly accessible to single-strand specific probes. Editing in the CYb mRNA is different from A6 because it involves only uridylate insertions. In contrast, editing in A6 begins with a deletional event followed by insertional editing at sites 2 and 3, with site 4 requiring another deletional event. Small structural differences surrounding the immediate editing site, like the ones found in this study, may be important for recognition by the correct editosome subcomplex, as suggested previously (Schnaufer et al. 2003; Panigrahi et al. 2006, 2007). Differences in the efficiency of full-round editing assays have also been found according to the type of ES within the same mRNA and between distinct mRNAs, supporting the idea that small structural differences can influence editosome assembly (Cifuentes-Rojas et al. 2005).

In summary, structure probing of the A6/gA6-14 editing pair indicates that the overall structure formed between the initiating gRNA and its cognate mRNA involves the formation of three helices that interact to stabilize the RNA bimolecular complex. Similar to the previously studied $\mathrm{CYb} / \mathrm{gCYb}-558$, the gRNA stem-loop is maintained in its initial interaction with the mRNA, and the U-tail forms a helix with purine-rich mRNA sequences just upstream of the first few editing sites. Formation of the U-tail helix helps stabilize both the gRNA stem-loop and the anchor helix. In addition, we show that the gA6-14 stem-loop is also maintained during the initial editing events. The overall secondary structure for the A6/gA6-14 complex was very similar to that observed for the $\mathrm{CYb} / \mathrm{gCYb} 558$ interaction, except for peculiar differences in the structure surrounding the immediate editing site. While the CYbU insertional site was found to be open and accessible to ssRNA probes, both of the A6 deletional sites were found to be within highly organized regions.

\section{MATERIALS AND METHODS}

\section{Oligodeoxynucleotides (ODN)}

All ODNs (Table 1) were chemically synthesized and obtained from Integrated DNA Technologies, Inc.

\section{Oligoribonucleotides}

The oligoribonucleotides below were chemically synthesized and obtained from Dharmacon Research, Inc. The C6-tail was obtained from Integrated DNA technologies:

$\mathrm{U}_{15}$-tail (15 nt): 5'-UUUUUUUUUUUUUUU- $3^{\prime}$;

C6-tail (15 nt): 5'-UUUCCCUUUCUUCUC-3';

U5-tail (15 nt): $5^{\prime}$-UUUU-s ${ }^{4} U-U U U U U U U U U U-3^{\prime}$; and

U10-tail (15 nt): $5^{\prime}$-UUUUUUUUU-s ${ }^{4} U-U U U U U-3^{\prime}$.

\section{DNA templates and RNA synthesis and modification}

The procedures below have been previously described (Leung and Koslowsky 2001a; Koslowsky et al. 2004; Yu and Koslowsky 2006). DNA templates were PCR amplifications from plasmids. The mRNAs were synthesized either by T7 RNA polymerase (RiboMax, Promega) according to the manufacturer's directions or in the presence of $5 \mathrm{mM}$ guanosine. Templates for gRNA synthesis 
TABLE 1. List of oligodeoxynucleotides

\begin{tabular}{|c|c|c|}
\hline ODN & $\begin{array}{l}\text { Sequence } \\
\left(5^{\prime} \text { to } 3^{\prime}\right)\end{array}$ & $\begin{array}{c}\text { Length } \\
\text { (nt) }\end{array}$ \\
\hline gA6-14sU & TAATTATCATATCACTGTCAAAATCTGATTCGTTATCGGAGTTATAGCСCTATAGTGAGTCGTATTAAATT & 71 \\
\hline gA6-14 & $\begin{array}{l}\text { AAAAAAAAAAAAAAATAATTATCATATCACTGTCAAAATCTGATTCGTTATCGGAGTTATAGCCCTATAG } \\
\text { TGAGTCGTATTAAATT }\end{array}$ & 86 \\
\hline T7-22 & AATTTAATACGACTCACTATAG & 22 \\
\hline bridge g14 & AAAAAAAAAAAATAATTATCATAT & 24 \\
\hline bridge gC6 & GAGAAGAAAGGGAAATAATTATCATATCAC & 30 \\
\hline RT-1 & TATTATTAACTTATTTGATCTTATTCTATAAC & 32 \\
\hline RT-2 & TATTATTAACTTATTTGATC & 20 \\
\hline RT-3 & TATTATTAACTTATTTG & 17 \\
\hline RT-4A6U & CTCCAAAATCACAАCTTTC & 19 \\
\hline RT-5A6P3 & СТССААТААСАААСААСТТТС & 21 \\
\hline A & GTTTGGCAAA & 10 \\
\hline B & тССТGСТСТт & 10 \\
\hline C & ССТААССТТТССТGС & 15 \\
\hline $\mathrm{D}$ & ТССТСССССТ & 10 \\
\hline E & ТТСТТСТСТССТСССССТ & 18 \\
\hline $\mathrm{F}$ & TCACAACTTT & 10 \\
\hline$F^{\prime}$ & CAAACAACTT & 10 \\
\hline G & CTATAACTCC & 10 \\
\hline
\end{tabular}

were prepared by hybridizing the T7-22 ODN to gA6-14sU and gA6-14 ODNs. The transcription of the gRNAs was based on the Uhlenbeck single-stranded T7 transcription using T7 RNA polymerase (Ambion, Inc.) (Milligan et al. 1987; Milligan and Uhlenbeck 1989). The gRNAs were synthesized in the presence (Burgin and Pace 1990; Harris and Christian 1999) or in the absence of $10 \mathrm{mM}$ guanosine $5^{\prime}$-monophosphorothioate (GMPS; Biolog Life Science Institutes or Dr. Harris's laboratory). In addition these transcripts also contained traces of $\left[\alpha-{ }^{32} \mathrm{P}\right]$ rATP (Perkin Elmer) for visualization and recovery. Half of the GMPSgA6-14sU transcripts were ligated to a $5^{\prime}$-end-labeled $\mathrm{U}_{15}$-tail. Half of the sample containing the thiol group at the $5^{\prime}$-end (GMPS-gRNA) was then coupled to azidophenacyl bromide. $5^{\prime}$ End labeling was performed with T4 Polynucleotide Kinase (Invitrogen) and $300 \mu \mathrm{Ci}$ of $\left[\gamma^{-}{ }^{32} \mathrm{P}\right]$ ATP for $1 \mathrm{nmol}$ of $\mathrm{U}_{15}$, $\mathrm{U} 5$, or U10-tail, $50 \mu \mathrm{Ci}$ for $25 \mathrm{pmol}$ of free mRNA, or $10 \mathrm{pmol}$ of cross-linked mRNA or for 20 pmol of ODN for primer extension analyses. $3^{\prime}$-End labeling involved ligation of $130 \mu \mathrm{Ci}(43 \mathrm{pmol})$ of cytidine $3^{\prime}, 5^{\prime}$-biphosphate (pCp) to about 500 pmol of GMPSgA6-14sU and GMPS-gA6-14 with T4 RNA ligase (New England Biolabs) as per the manufacturer's directions. RNA products were separated by electrophoresis on $8 \%(\mathrm{w} / \mathrm{v})$ (mRNA) or $15 \%(\mathrm{w} / \mathrm{v})$ (gRNA) polyacrylamide gels containing $8 \mathrm{M}$ urea and eluted overnight in elution buffer $(10 \mathrm{mM}$ Tris at $\mathrm{pH} 7.8,0.1 \%$ SDS, $2 \mathrm{mM}$ EDTA, and $0.3 \mathrm{M} \mathrm{NaOAc}$ at $\mathrm{pH} 7.0$ ) in the presence of phenol. The RNA concentrations were determined by measuring the absorbance at $260 \mathrm{~nm}$, using a Cary 50 spectrophotometer.

\section{RNA cross-linking}

Reactions involved the cross-link of gRNA to the mRNA as described before (Leung and Koslowsky 1999). The gRNA contained either 4-thio-U ( $\left.S^{4} \mathrm{U}\right)$ or APA groups. Briefly, 50-200 pmol of gRNA were annealed to mRNA ( 3 mol excess) in HE buffer ( 25
nM HEPES at pH 7.5, $2 \mathrm{mM}$ MgOAc, $50 \mathrm{mM} \mathrm{KCl}, 0.5 \mathrm{mM}$ DTT, $0.1 \mathrm{mM}$ EDTA) by heating to $50^{\circ} \mathrm{C}$, cooling $3^{\circ} \mathrm{C} / \mathrm{min}$ to $27^{\circ} \mathrm{C}$, and incubating at $27^{\circ} \mathrm{C}$ for $45 \mathrm{~min}$. The hybridized RNAs were placed on ice and irradiated at a distance of $5 \mathrm{~cm}$ from Stratalinker (Stratagene) $312 \mathrm{~nm}$ bulbs for $20 \mathrm{~min}$. Cross-linked molecules were ethanol precipitated and gel extracted. The efficiency of cross-links was obtained by exposing the gel to a phosphor screen and using a Storm PhosphorImager (Molecular Dynamics). The cross-links were further mapped and confirmed through primer extension and RNase $\mathrm{H}$ analysis, respectively. Alternatively, the cross-linked mRNA was 5 '-end labeled using T4 kinase to proceed with solution structure probing.

\section{Primer extension analysis}

The primer extension procedure has been described before (Leung and Koslowsky 1999). Briefly, $50 \mathrm{Kcpm}$ of a $5^{\prime}$-end-labeled primer (we used five different RT ODNs) are hybridized to the cross-linked RNAs or 2-5 ng of control mRNA in RT buffer $(50 \mathrm{mM} \mathrm{KCl}, 20$ $\mathrm{mM}$ Tris- $\mathrm{HCl}$ at $\mathrm{pH} 8.5,0.5 \mathrm{mM}$ EDTA, and $8 \mathrm{mM} \mathrm{MgCl}_{2}$ ). Then, an extension cocktail containing $0.25 \mathrm{U}$ of AMV reverse transcriptase (Seikagaku) and all four dNTPs ( $1.6 \mathrm{mM}$ each) is added. Primer extension is carried out at $50^{\circ} \mathrm{C}$ for $30 \mathrm{~min}$ and stopped by addition of formamide loading buffer (95\% formamide, $20 \mathrm{mM}$ EDTA, $0.05 \%$ bromophenol blue, and $0.05 \%$ xylene cyanol). Sequencing reactions required $0.8 \mathrm{mM}$ of each $\mathrm{dNTP}$ and 0.4 $\mathrm{mM}$ of each ddNTP per reaction. Reactions were resolved on $8 \%-$ $10 \%(\mathrm{w} / \mathrm{v})$ denaturing polyacrylamide gels that were exposed to a phosphor screen and analyzed using a Storm PhosphorImager.

\section{RNase $\mathrm{H}$ assays}

The assay has been described before (Leung and Koslowsky 1999). Briefly, 20 pmol of ODN (A, B, C, D, E, F, F' , or G) are incubated 
with $\sim 1000 \mathrm{cpm}$ of the cross-linked molecules, $20 \mathrm{pmol}$ of nonlabeled mRNA of the same species, and $2 \mathrm{U}$ of RNase $\mathrm{H}$ (Takara). The digestion is held at $55^{\circ} \mathrm{C}$ for $30 \mathrm{~min}$, under $40 \mathrm{mM}$ Tris-HCl (pH 7.5), $100 \mathrm{mM} \mathrm{KCl,} 2 \mathrm{mM} \mathrm{MgCl}$, $1 \mathrm{mM} \mathrm{DTT}$, and stopped by addition of formamide loading buffer. Reactions were resolved on $6 \%(\mathrm{w} / \mathrm{v})$ denaturing polyacrylamide gels that were exposed to a phosphor screen and analyzed using a Storm PhosphorImager.

\section{Secondary structure prediction}

The mfold computer program (Walter et al. 1994; Zuker 2003) was used to predict the secondary structure of single molecule RNAs used in the present study. The bimolecular secondary structure (mRNA/gRNA) was obtained by RNAstructure version 4.5 (Mathews et al. 2004) or mfold (entering the mRNA and gRNA sequences joined by a linker of three non-base-pairing $\mathrm{N}$ residues).

\section{Solution structure probing}

Experiments were performed using non-cross-linked or crosslinked mRNA/gRNA pairs ( $5^{\prime}$-end of gRNA cross-linked to $3^{\prime}$-end of mRNA ABS).

\section{Enzymatic probing}

The labeled cross-link or non-cross-linked RNA (200 Kcpm) and the unlabeled partner $(0.5-1.5 \mathrm{pmol})$ were hybridized in structure probing buffer (SPB, $10 \mathrm{mM}$ Tris- $\mathrm{HCl}$ at $\mathrm{pH} 7.5,100 \mathrm{mM} \mathrm{KCl}, 10$ $\mathrm{mM} \mathrm{MgCl}_{2}$ ) by heating for $3 \mathrm{~min}$ at $70^{\circ} \mathrm{C}$, or at $55^{\circ} \mathrm{C}$ if crosslinked, slowly cooling down to $27^{\circ} \mathrm{C}$, and keeping at $27^{\circ} \mathrm{C}$ for $30 \mathrm{~min}$ (if cross-linked) or $3 \mathrm{~h}$ (if non-cross-linked). After the no enzyme (NE) control aliquot was taken, $10 \mu \mathrm{g}$ of yeast tRNA were added with one of the following enzymes: $0.1 \mathrm{U}$ RNase T1 (Industrial Research, Ltd.), 0.3 U RNase T2 (Invitrogen), $0.25 \mathrm{U}$ Mung Bean Nuclease (MB, New England Biolabs), or $0.1 \mathrm{U}$ V1 (cobra venom, Pierce M.B.). RNA digestion was conducted at $27^{\circ} \mathrm{C}$, followed by withdrawal of 10 - or $20 \mu \mathrm{L}$ aliquots at two or three time points. The reaction was stopped at $4^{\circ} \mathrm{C}$ by addition of TE (10 mM Tris- $\mathrm{HCl}$ at $\mathrm{pH} 7.0,0.1 \mathrm{mM}$ EDTA) and phenol, followed by phenol/chloroform/isoamyl alcohol (25:24:1) extraction and ethanol precipitation.

\section{Chemical probing}

Diethylpyrocarbonate (DEPC; Aldrich) carbethoxylates the atom $\mathrm{N} 7$ of adenosines, at neutral $\mathrm{pH}$, that are not involved in helices. This modification opens the imidazole ring between atoms N7 and $\mathrm{C} 8$, creating a site for aniline strand scission. The end product is $\mathrm{N} 7-\mathrm{CO}_{2} \mathrm{H}_{2}$, which runs slower on a gel, compared to cleavages performed by RNases $\mathrm{T} 1$ and $\mathrm{T} 2$. The reactions were set up as for enzymatic probing as above, then $\sim 6 \mu \mathrm{L}$ of DEPC were added and incubated at $27^{\circ} \mathrm{C}$ for different time points. Reactions were stopped by addition of TE buffer and ethanol precipitated twice in $0.3 \mathrm{M}$ sodium acetate ( $\mathrm{pH}$ 6). Pellets were suspended in $20 \mu \mathrm{L}$ of a solution containing $1 \mathrm{M}$ aniline (Aldrich) $(\mathrm{pH} 4.5)$. Strand scission was performed at $55^{\circ} \mathrm{C}$ for $20 \mathrm{~min}$ in the dark and stopped by double ethanol precipitation. The above treated RNAs were suspended in formamide loading buffer and analyzed on
$12 \%$ or $15 \%(\mathrm{w} / \mathrm{v})$ denaturing polyacrylamide gels. RNA ladders $(20 \mu \mathrm{L})$ were generated by enzymatic digestion of heat denatured RNAs at $55^{\circ} \mathrm{C}$ for $8 \mathrm{~min}$ in buffer I $(33 \mathrm{mM}$ sodium citrate at $\mathrm{pH}$ 5.0, $1.7 \mathrm{mM}$ EDTA, $7 \mathrm{M}$ urea, $0.04 \%$ xylene cyanol, $0.08 \%$ bromophenol blue) when digesting with T1 $(0.028 \mathrm{U})$ or MB (2 $\mathrm{U}$ ) and buffer II (33 mM sodium citrate at $\mathrm{pH} 3.5,1.7 \mathrm{mM}$ EDTA, $7 \mathrm{M}$ urea, $0.04 \%$ xylene cyanol, $0.08 \%$ bromophenol blue) when digesting with $\mathrm{U} 2(0.1 \mathrm{U})$ or T2 $(0.0004 \mathrm{U})$. Gels were exposed to a phosphor screen and analyzed by PhosphorImager using ImageQuant software from Storm PhosphorImager (Molecular Dynamics).

\section{ACKNOWLEDGMENTS}

This work was supported by NIH grant AI34155 to D.J.K. We thank Dr. Brenda Peculis at NIH for sharing her buffer recipes and digestion conditions and Dr. Michael Harris from Case Western University for samples of GMPS and technical advice. We also thank Dr. Laura Yu for helping with experimental procedures and data analyses.

Received April 18, 2008; accepted July 17, 2008.

\section{REFERENCES}

Abraham, J.M., Feagin, J.E., and Stuart, K. 1988. Characterization of cytochrome c oxidase III transcripts that are edited only in the $3^{\prime}$ region. Cell 55: 267-272.

Adler, B.K. and Hajduk, S.L. 1997. Guide RNA requirement for editing-site-specific endonucleolytic cleavage of preedited mRNA by mitochondrial ribonucleoprotein particles in Trypanosoma brucei. Mol. Cell. Biol. 17: 5377-5385.

Ammerman, M.L., Fisk, J.C., and Read, L.K. 2008. gRNA/pre-mRNA annealing and RNA chaperone activities of RBP16. RNA 14: 10691080.

Aphasizhev, R., Aphasizheva, I., Nelson, R.E., and Simpson, L. 2003. A $100-\mathrm{kD}$ complex of two RNA-binding proteins from mitochondria of Leishmania tarentolae catalyzes RNA annealing and interacts with several RNA editing components. RNA 9: 62-76.

Auron, P.E., Weber, L.D., and Rich, A. 1982. Comparison of transfer ribonucleic acid structures using cobra venom and S1 endonucleases. Biochemistry 21: 4700-4706.

Bernal, J.J. and Garcia-Arenal, F. 1997. Analysis of the in vitro secondary structure of cucumber mosaic virus satellite RNA. RNA 3: 1052-1067.

Bhat, G.J., Koslowsky, D.J., Feagin, J.E., Smiley, B.L., and Stuart, K. 1990. An extensively edited mitochondrial transcript in kinetoplastids encodes a protein homologous to ATPase subunit 6. Cell 61: 885-894.

Blom, D., Burg, J., Breek, C.K., Speijer, D., Muijsers, A.O., and Benne, R. 2001. Cloning and characterization of two guide RNAbinding proteins from mitochondria of Crithidia fasciculata: gBP27, a novel protein, and gBP29, the orthologue of Trypanosoma brucei gBP21. Nucleic Acids Res. 29: 2950-2962.

Blum, B. and Simpson, L. 1990. Guide RNAs in kinetoplastid mitochondria have a nonencoded $3^{\prime}$ oligo(U) tail involved in recognition of the preedited region. Cell 62: 391-397.

Blum, B., Bakalara, N., and Simpson, L. 1990. A model for RNA editing in kinetoplastid mitochondria: "Guide" RNA molecules transcribed from maxicircle DNA provide the edited information. Cell 60: 189-198.

Brunel, C., Romby, P., Westhof, E., Ehresmann, C., and Ehresmann, B. 1991. Three-dimensional model of Escherichia coli ribosomal $5 \mathrm{~S}$ RNA as deduced from structure probing 
in solution and computer modeling. J. Mol. Biol. 221: 293308.

Burgess, M.L., Heidmann, S., and Stuart, K. 1999. Kinetoplastid RNA editing does not require the terminal 3' hydroxyl of guide RNA, but modifications to the guide RNA terminus can inhibit in vitro U insertion. RNA 5: 883-892.

Burgin, A.B. and Pace, N.R. 1990. Mapping the active site of ribonuclease P RNA using a substrate containing a photoaffinity agent. EMBO J. 9: 4111-4118.

Burkard, M.E., Turner, C.M., and Tinoco Jr., I. 1999. The interactions that shape RNA structure. In The RNA world, 2nd ed (eds. R.F. Gesteland et al.), p. 709. Cold Spring Harbor Laboratory Press, Cold Spring Harbor, NY.

Butcher, S.E., Dieckmann, T., and Feigon, J. 1997. Solution structure of a GAAA tetraloop receptor RNA. EMBO J. 16: 74907499.

Byrne, E.M., Connell, G.J., and Simpson, L. 1996. Guide RNAdirected uridine insertion RNA editing in vitro. $E M B O$ J. 15: $6758-6765$.

Carnes, J., Trotter, J.R., Peltan, A., Fleck, M., and Stuart, K. 2008. RNA editing in Trypanosoma brucei requires three different editosomes. Mol. Cell. Biol. 28: 122-130.

Cech, T.R., Tanner, N.K., Tinoco Jr., I., Weir, B.R., Zuker, M., and Perlman, P.S. 1983. Secondary structure of the Tetrahymena ribosomal RNA intervening sequence: Structural homology with fungal mitochondrial intervening sequences. Proc. Natl. Acad. Sci. 80: 3903-3907.

Cifuentes-Rojas, C., Halbig, K., Sacharidou, A., De NovaOcampo, M., and Cruz-Reyes, J. 2005. Minimal pre-mRNA substrates with natural and converted sites for full-round $U$ insertion and $\mathrm{U}$ deletion RNA editing in trypanosomes. Nucleic Acids Res. 33: 6610-6620.

Cifuentes-Rojas, C., Pavia, P., Hernandez, A., Osterwisch, D., Puerta, C., and Cruz-Reyes, J. 2007. Substrate determinants for RNA editing and editing complex interactions at a site for fullround U insertion. J. Biol. Chem. 282: 4265-4276.

Connell, G.J. and Simpson, L. 1998. Role of RNA structure in RNA editing. In RNA structure and function (eds. R.W. Simons and M. Grunberg-Manago), pp. 641-667. Cold Spring Harbor Laboratory Press, Cold Spring Harbor, NY.

Corell, R.A., Read, L.K., Riley, G.R., Nellissery, J.K., Allen, T.E., Kable, M.L., Wachal, M.D., Seiwert, S.D., Myler, P.J., and Stuart, K.D. 1996. Complexes from Trypanosoma brucei that exhibit deletion editing and other editing-associated properties. Mol. Cell. Biol. 16: 1410-1418.

Cruz-Reyes, J. and Sollner-Webb, B. 1996. Trypanosome U-deletional RNA editing involves guide RNA-directed endonuclease cleavage, terminal U exonuclease, and RNA ligase activities. Proc. Natl. Acad. Sci. 93: 8901-8906.

Cruz-Reyes, J., Rusche, L.N., and Sollner-Webb, B. 1998. Trypanosoma brucei $\mathrm{U}$ insertion and $\mathrm{U}$ deletion activities co-purify with an enzymatic editing complex but are differentially optimized. Nucleic Acids Res. 26: 3634-3639.

Cruz-Reyes, J., Zhelonkina, A., Rusche, L., and Sollner-Webb, B. 2001. Trypanosome RNA editing: Simple guide RNA features enhance U deletion 100-fold. Mol. Cell. Biol. 21: 884-892.

Dubreuil, Y.L., Expert-Bezancon, A., and Favre, A. 1991. Conformation and structural fluctuations of a 218 nucleotides long rRNA fragment: 4-Thiouridine as an intrinsic photolabelling probe. Nucleic Acids Res. 19: 3653-3660.

Ehresmann, C., Baudin, F., Mougel, M., Romby, P., Ebel, J.P., and Ehresmann, B. 1987. Probing the structure of RNAs in solution. Nucleic Acids Res. 15: 9109-9128.

Favre, A., Saintome, C., Fourrey, J.L., Clivio, P., and Laugaa, P. 1998. Thionucleobases as intrinsic photoaffinity probes of nucleic acid structure and nucleic acid-protein interactions. J. Photochem. Photobiol. B 42: 109-124.

Freier, S.M., Kierzek, R., Jaeger, J.A., Sugimoto, N., Caruthers, M.H., Neilson, T., and Turner, D.H. 1986. Improved free-energy param- eters for predictions of RNA duplex stability. Proc. Natl. Acad. Sci. 83: 9373-9377.

Golden, D.E. and Hajduk, S.L. 2006. The importance of RNA structure in RNA editing and a potential proofreading mechanism for correct guide RNA:pre-mRNA binary complex formation. $J$. Mol. Biol. 359: 585-596.

Harris, M.E. and Christian, E.L. 1999. Use of circular permutation and end modification to position photoaffinity probes for analysis of RNA structure. Methods 18: 51-59.

Hermann, T., Schmid, B., Heumann, H., and Goringer, H.U. 1997. A three-dimensional working model for a guide RNA from Trypanosoma brucei. Nucleic Acids Res. 25: 2311-2318.

Igo Jr., R.P., Palazzo, S.S., Burgess, M.L., Panigrahi, A.K., and Stuart, K. 2000. Uridylate addition and RNA ligation contribute to the specificity of kinetoplastid insertion RNA editing. Mol. Cell. Biol. 20: 8447-8457.

Igo Jr., R.P., Lawson, S.D., and Stuart, K. 2002. RNA sequence and base pairing effects on insertion editing in Trypanosoma brucei. Mol. Cell. Biol. 22: 1567-1576.

Kable, M.L., Seiwert, S.D., Heidmann, S., and Stuart, K. 1996. RNA editing: A mechanism for gRNA-specified uridylate insertion into precursor mRNA. Science 273: 1189-1195.

Kang, X., Rogers, K., Gao, G., Falick, A.M., Zhou, S., and Simpson, L. 2005. Reconstitution of uridine-deletion precleaved RNA editing with two recombinant enzymes. Proc. Natl. Acad. Sci. 102: 10171022.

Kapushoc, S.T. and Simpson, L. 1999. In vitro uridine insertion RNA editing mediated by cis-acting guide RNAs. RNA 5: 656669.

Knapp, G. 1989. Enzymatic approaches to probing of RNA secondary and tertiary structure. Methods Enzymol. 180: 192-212.

Koller, J., Muller, U.F., Schmid, B., Missel, A., Kruft, V., Stuart, K., and Goringer, H.U. 1997. Trypanosoma brucei gBP21. An argininerich mitochondrial protein that binds to guide RNA with high affinity. J. Biol. Chem. 272: 3749-3757.

Koslowsky, D.J. 2004. A historical perspective on RNA editing: How the peculiar and bizarre became mainstream. Methods Mol. Biol. 265: $161-197$.

Koslowsky, D.J., Bhat, G.J., Read, L.K., and Stuart, K. 1991. Cycles of progressive realignment of gRNA with mRNA in RNA editing. Cell 67: $537-546$.

Koslowsky, D.J., Reifur, L., Yu, L.E., and Chen, W. 2004. Evidence for U-tail stabilization of gRNA/mRNA interactions in kinetoplastid RNA editing. RNA Biol. 1: 28-34.

Krol, A., Westhof, E., Bach, M., Luhrmann, R., Ebel, J.P., and Carbon, P. 1990. Solution structure of human U1 snRNA. Derivation of a possible three-dimensional model. Nucleic Acids Res. 18: 3803-3811.

Lawson, S.D., Igo Jr., R.P., Salavati, R., and Stuart, K.D. 2001. The specificity of nucleotide removal during RNA editing in Trypanosoma brucei. RNA 7: 1793-1802.

Lescoute, A. and Westhof, E. 2006. Topology of three-way junctions in folded RNAs. RNA 12: 83-93.

Leung, S.S. and Koslowsky, D.J. 1999. Mapping contacts between gRNA and mRNA in trypanosome RNA editing. Nucleic Acids Res. 27: 778-787.

Leung, S.S. and Koslowsky, D.J. 2001a. Interactions of mRNAs and gRNAs involved in trypanosome mitochondrial RNA editing: Structure probing of an mRNA bound to its cognate gRNA. RNA 7: 1803-1816.

Leung, S.S. and Koslowsky, D.J. 2001b. RNA editing in Trypanosoma brucei: Characterization of gRNA U-tail interactions with partially edited mRNA substrates. Nucleic Acids Res. 29: 703-709.

Lockard, R.E. and Kumar, A. 1981. Mapping tRNA structure in solution using double-strand-specific ribonuclease V1 from cobra venom. Nucleic Acids Res. 9: 5125-5140.

Lowman, H.B. and Draper, D.E. 1986. On the recognition of helical RNA by cobra venom V1 nuclease. J. Biol. Chem. 261: 53965403. 
Madison-Antenucci, S., Grams, J., and Hajduk, S.L. 2002. Editing machines: The complexities of trypanosome RNA editing. Cell 108: $435-438$.

Maslov, D.A. and Simpson, L. 1992. The polarity of editing within a multiple gRNA-mediated domain is due to formation of anchors for upstream gRNAs by downstream editing. Cell 70: 459-467.

Mathews, D.H., Disney, M.D., Childs, J.L., Schroeder, S.J., Zuker, M., and Turner, D.H. 2004. Incorporating chemical modification constraints into a dynamic programming algorithm for prediction of RNA secondary structure. Proc. Natl. Acad. Sci. 101: 7287-7292.

Miller, M.M., Halbig, K., Cruz-Reyes, J., and Read, L.K. 2006. RBP16 stimulates trypanosome RNA editing in vitro at an early step in the editing reaction. RNA 12: 1292-1303.

Milligan, J.F. and Uhlenbeck, O.C. 1989. Synthesis of small RNAs using T7 RNA polymerase. Methods Enzymol. 180: 51-62.

Milligan, J.F., Groebe, D.R., Witherell, G.W., and Uhlenbeck, O.C. 1987. Oligoribonucleotide synthesis using T7 RNA polymerase and synthetic DNA templates. Nucleic Acids Res. 15: 8783-8798.

Muller, U.F. and Goringer, H.U. 2002. Mechanism of the gBP21mediated RNA/RNA annealing reaction: Matchmaking and charge reduction. Nucleic Acids Res. 30: 447-455.

Panigrahi, A.K., Allen, T.E., Stuart, K., Haynes, P.A., and Gygi, S.P. 2003. Mass spectrometric analysis of the editosome and other multiprotein complexes in Trypanosoma brucei. J. Am. Soc. Mass Spectrom. 14: 728-735.

Panigrahi, A.K., Ernst, N.L., Domingo, G.J., Fleck, M., Salavati, R., and Stuart, K.D. 2006. Compositionally and functionally distinct editosomes in Trypanosoma brucei. RNA 12: 1038-1049.

Panigrahi, A.K., Schnaufer, A., and Stuart, K.D. 2007. Isolation and compositional analysis of trypanosomatid editosomes. Methods Enzymol. 424: 3-24.

Peattie, D.A. 1979. Direct chemical method for sequencing RNA. Proc. Natl. Acad. Sci. 76: 1760-1764.

Peterson, R.D. and Feigon, J. 1996. Structural change in Rev responsive element RNA of HIV-1 on binding Rev peptide. J. Mol. Biol. 264: 863-877.

Pollard, V.W., Harris, M.E., and Hajduk, S.L. 1992. Native mRNA editing complexes from Trypanosoma brucei mitochondria. EMBO J. 11: 4429-4438.

Reenan, R.A. 2005. Molecular determinants and guided evolution of species-specific RNA editing. Nature 434: 409-413.

Rusche, L.N., Cruz-Reyes, J., Piller, K.J., and Sollner-Webb, B. 1997. Purification of a functional enzymatic editing complex from Trypanosoma brucei mitochondria. EMBO J. 16: 4069-4081.

Sacharidou, A., Cifuentes-Rojas, C., Halbig, K., Hernandez, A., Dangott, L.J., De Nova-Ocampo, M., and Cruz-Reyes, J. 2006. RNA editing complex interactions with a site for full-round $\mathrm{U}$ deletion in Trypanosoma brucei. RNA 12: 1219-1228.

Schmid, B., Riley, G.R., Stuart, K., and Goringer, H.U. 1995. The secondary structure of guide RNA molecules from Trypanosoma brucei. Nucleic Acids Res. 23: 3093-3102.

Schnaufer, A., Ernst, N.L., Palazzo, S.S., O’Rear, J., Salavati, R., and Stuart, K. 2003. Separate insertion and deletion subcomplexes of the Trypanosoma brucei RNA editing complex. Mol. Cell 12: 307-319.

Schroeder, R., Barta, A., and Semrad, K. 2004. Strategies for RNA folding and assembly. Nat. Rev. Mol. Cell Biol. 5: 908-919.

Schumacher, M.A., Karamooz, E., Zikova, A., Trantirek, L., and Lukes, J. 2006. Crystal structures of T. brucei MRP1/MRP2
guide-RNA binding complex reveal RNA matchmaking mechanism. Cell 126: 701-711.

Seiwert, S.D. and Stuart, K. 1994. RNA editing: Transfer of genetic information from gRNA to precursor mRNA in vitro. Science 266: 114-117.

Seiwert, S.D., Heidmann, S., and Stuart, K. 1996. Direct visualization of uridylate deletion in vitro suggests a mechanism for kinetoplastid RNA editing. Cell 84: 831-841.

Simpson, L., Sbicego, S., and Aphasizhev, R. 2003. Uridine insertion/ deletion RNA editing in trypanosome mitochondria: A complex business. RNA 9: 265-276.

Simpson, L., Aphasizhev, R., Gao, G., and Kang, X. 2004. Mitochondrial proteins and complexes in Leishmania and Trypanosoma involved in U-insertion/deletion RNA editing. RNA 10: 159170.

Sontheimer, E.J. 1994. Site-specific RNA crosslinking with 4-thiouridine. Mol. Biol. Rep. 20: 35-44.

Stuart, K.D., Schnaufer, A., Ernst, N.L., and Panigrahi, A.K. 2005 Complex management: RNA editing in trypanosomes. Trends Biochem. Sci. 30: 97-105.

Sturm, N.R. and Simpson, L. 1990. Partially edited mRNAs for cytochrome $\mathrm{b}$ and subunit III of cytochrome oxidase from Leishmania tarentolae mitochondria: RNA editing intermediates. Cell 61: 871-878.

Thomas, B.C., Kazantsev, A.V., Chen, J.L., and Pace, N.R. 2000. Photoaffinity cross-linking and RNA structure analysis. Methods Enzymol. 318: 136-147.

Vondruskova, E., van den Burg, J., Zikova, A., Ernst, N.L., Stuart, K., Benne, R., and Lukes, J. 2005. RNA interference analyses suggest a transcript-specific regulatory role for mitochondrial RNA-binding proteins MRP1 and MRP2 in RNA editing and other RNA processing in Trypanosoma brucei. J. Biol. Chem. 280: 2429-2438.

Walter, A.E., Turner, D.H., Kim, J., Lyttle, M.H., Muller, P., Mathews, D.H., and Zuker, M. 1994. Coaxial stacking of helixes enhances binding of oligoribonucleotides and improves predictions of RNA folding. Proc. Natl. Acad. Sci. 91: 9218-9222.

Westhof, E., Romby, P., Romaniuk, P.J., Ebel, J.P., Ehresmann, C., and Ehresmann, B. 1989. Computer modeling from solution data of spinach chloroplast and of Xenopus laevis somatic and oocyte 5 S rRNAs. J. Mol. Biol. 207: 417-431.

$\mathrm{Yu}$, L.E. and Koslowsky, D.J. 2006. Interactions of mRNAs and gRNAs involved in trypanosome mitochondrial RNA editing: Structure probing of a gRNA bound to its cognate mRNA. RNA 12: 10501060.

Zikova, A., Kopecna, J., Schumacher, M.A., Stuart, K., Trantirek, L., and Lukes, J. 2008. Structure and function of the native and recombinant mitochondrial MRP1/MRP2 complex from Trypanosoma brucei. Int. J. Parasitol. 31: 901-912.

Zimmermann, G.R., Jenison, R.D., Wick, C.L., Simorre, J.P., and Pardi, A. 1997. Interlocking structural motifs mediate molecular discrimination by a theophylline-binding RNA. Nat. Struct. Biol. 4: 644-649.

Znosko, B.M., Kennedy, S.D., Wille, P.C., Krugh, T.R., and Turner, D.H. 2004. Structural features and thermodynamics of the J4/5 loop from the Candida albicans and Candida dubliniensis group I introns. Biochemistry 43: 15822-15837.

Zuker, M. 2003. Mfold web server for nucleic acid folding and hybridization prediction. Nucleic Acids Res. 31: 3406-3415. 

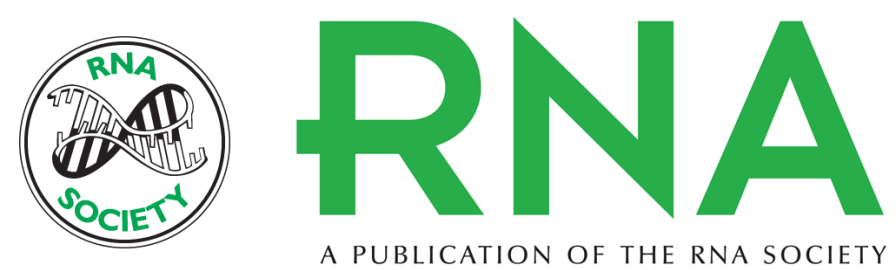

\section{Trypanosoma brucei ATPase subunit 6 mRNA bound to gA6-14 forms a conserved three-helical structure}

Larissa Reifur and Donna J. Koslowsky

RNA 2008 14: 2195-2211 originally published online September 4, 2008

Access the most recent version at doi:10.1261/rna.1144508

References This article cites 84 articles, 34 of which can be accessed free at:

http://rnajournal.cshlp.org/content/14/10/2195.full.html\#ref-list-1

License

Email Alerting Receive free email alerts when new articles cite this article - sign up in the box at the Service top right corner of the article or click here. 